\title{
GRAVITY SURVEYING IN EARLY GEOPHYSICS. I. FROM TIME-KEEPING TO FIGURE OF THE EARTH
}

\author{
RichaRd J. HOWARTH \\ Department of Earth Sciences, University College London, \\ Gower Street, London WC1E 6BT, UK (r.howarth@ucl.ac.uk)
}

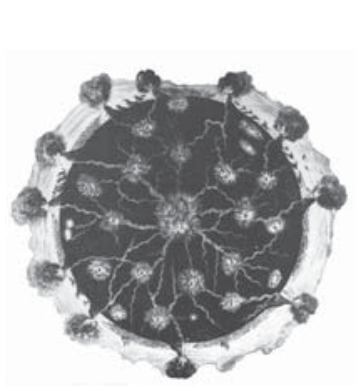

Earth Sciences History, v. 26 , no. 2, 2007, pp. 201-228.

\begin{abstract}
This two-part review of the development of the measurement of the Earth's gravity field, and its application to geology, up to the early 1960 s, is intended primarily for an earth-science readership. The focus here is on the pendulum, which played the dominant role in measurement of the intensity of gravity $(g)$, both in absolute (at national observatories) and relative terms (at field stations), until the early twentieth century. Following discovery of the properties of the pendulum and its incorporation in time-keepers, early post-Newtonian investigations used the length of a pendulum beating seconds as a proxy for $g$. The goal was to obtain ever-improved knowledge of the "Figure of the Earth," initially encapsulated in determination of the degree of flattening of the oblate ellipsoid used as a model for the geometry of the globe. Developments in theory went hand-in-hand with both improvements in pendulum design and the establishment of a constantly expanding network of astrogeodetic stations as a basis for national cartographic surveys. By the late nineteenth century, results from astrogeodetic determinations of the length of a degree of arc and those derived from gravity determinations (by means of Clairaut's theorem) had converged to an inverse flattening of 298 , and emphasis switched to determination of the geoid. However, by the 1840s, discrepancies between observed and model-fitted values were providing increasingly strong evidence that geological factors also affected the local value of $g$. This would give rise to the use of gravity determination as a geological exploration tool in the twentieth century.
\end{abstract}

\section{INTRODUCTION}

La détermination de la grandeur et de la figure de la terre, la mesure de la pesanteur à sa surface, la liasison de ce phénomène avec la constitution intérieure du globe, avec la disposition de ses couches et les lois de leurs densités, sont au nombre de ces questions de longe durée que des sociétés savantes seules pouvaient se proposer d'attaquer et de résoudre. Jean-Baptiste Biot (1818a, p. 33) ${ }^{1}$

The great importance of the results obtained by means of the pendulum has induced philosophers to devote so much attention to the subject, and to perform the experiments with such a scrupulous regard to accuracy in every particular, that pendulum observations may justly be ranked among those most distinguished by modern exactness. George Gabriel Stokes (1856)

1 The determination of the size and figure of the [E] arth, the measurement of the force of gravity at its surface, the relationship of these phenomena with the interior constitution of the globe, with the disposition of its layers and the laws of their densities, are among a number of questions of longstanding duration which only scientific societies are able to attack and resolve. 
This paper and its sequel review the development of the measurement of the Earth's gravitational field and application of the results to geology, up to the early 1960s. They are based on an invited keynote address to the INHIGEO Symposium on the History of Geophysics, held in Prague, July 2005, and their content is intended for geologists and geophysicists interested in the history of geophysics. No attempt is made at comprehensive coverage of all the instruments of each type (pendulums, torsion balances, gravimeters, etc.) developed over the years - useful sources of information include: Wolf (1889a, b, c), Heiland (1940), Jakosky (1940), Nettleton (1940), Lenzen \& Multhauf (1965) and Chapin (1998). Coverage of purely geodesic applications is limited; likewise, it is impractical to include biographical detail for all of the scientists involved in such work since the properties of the pendulum were first elucidated in Italy in 1583 by the Italian astronomer, mathematician and physicist, Galileo Galilei (1564-1642). Attention is mainly paid to those who have made contributions relevant to geophysical aspects of the subject. However, I begin with the earliest studies of the pendulum and its use in timekeeping, as this underpins the origins of my topic and is largely unknown to today's earth scientists.

A simple (theoretical) pendulum consists of a point mass at the end of a weightless inextensible thread. It may be approximated by a weight (the bob) suspended from a thread or fine wire from a fixed support. Such pendulums are today often referred to as "simple", the quotation marks indicating they are an approximation (Lenzen and Multhauf 1965), or referred to as plumb-lines. A real pendulum, in which the thread, wire or rod supporting the bob is not weightless, is known as a compound pendulum. In practice, the latter generally consists of a solid rod oscillating about a fixed axis under the action of its own weight. The distinction between simple and compound pendulums was first made by the Dutch mathematician and physicist, Christiaan Huygens (1629-1695) in, or before, 1661 (Société Hollandaise des Sciences, 1888-1950, 16: 414-433).

The complete period $(T)$ of a pendulum is the time it takes for its bob to swing from its extreme position on one side of the vertical centre-line to the mirror-image point on the other side and back again; or, equivalently, the elapsed time between the pendulum passing through any given position and its next passing through the identical position from the same direction. The time of vibration or the time of a single vibration $(t)$ is $T / 2$, the time of passing from one of the two extreme positions to the other. In general usage, a pendulum is detached, i.e. it is unconnected with machinery of any sort to maintain or regulate its oscillations, when set in motion it vibrates by the influence of gravity alone in arcs which progressively diminish as a result of the resistance of the air, until it eventually come to rest.

\section{THE PENDULUM AS TIME-KEEPER}

Despite an inherent lack of accuracy in Galileo Galilei's timing apparatus - he used as a measure the weight of the volume of water expelled from a large reservoir through a small-bore pipe in the time taken for a given number of oscillations - by comparing the behaviour of pendulums in which the bob was hung from suspension threads of different length $(l)$, he was able to establish that $T$ is proportional to the square root (a familiar concept by the sixteenth century) of $l$. Additional experiments, using two pendulums of the same length but with one bob made of cork, the other of lead, satisfied him that the period is independent of the material from which the bob is made. At some point between 1581 and 1589 , he also established that the period is isochronous, i.e. 
independent of the magnitude of the arc of swing. He recognised the potential of this idea for time-keeping and, by about 1640, had begun work on designs for a pendulum clock, but its successful construction remained unfulfilled at the time of his death. His ideas on the general properties of the pendulum were first published in 1632 and are given in more detail in his treatise on mechanics in 1638.

The most natural definition of a "day" is the period that elapses between two successive returns of the sun to a fixed position in the sky, but because of variations in the earth's orbit, this varies throughout the year and can be observed with a sun-dial. Such variation could be measured even with primitive water clocks, and by the second century AD, the Alexandrian astronomer Claudius Ptolemy (fl. AD 100-175) had established how to calculate the length of the mean solar day (Toomer 1984, pp. 169-170). Following on from Egyptian and Babylonian traditions, this came to be divided into 24 (equinoctial) hours of 60 minutes each and with 60 seconds per minute, i.e. $86400 \mathrm{~s}$. It thus became a matter of interest to construct a pendulum which would beat seconds but, because of a lack of an accurate time-keeper, the first experiments had to rest on a trial-and-error approach.

The first reported measurement of the length of such a pendulum, 3.5 [French] feet in a celestial day $(113.82 \mathrm{~cm})$, was obtained by the French physicist, Marin Mersenne (1588-1648) (Mersenne, 1636, 1, p. 220), although in later experiments (Mersenne, 1644 , p. 44) he preferred a shorter length. More accurate results (see Koyré 1953 for discussion) were independently obtained by the Italian astronomer, Giovanni Battista Riccioli (1598-1671) in the course of a long series of experiments conducted between 1640 and 1645, which began with careful confirmation of Galileo's results. Employing water-glass, sun-dial and stellar observation as timekeepers, by 1645 Riccioli had arrived at a length of 3 [Roman] feet 2.67 inches $(95.29 \mathrm{~cm})$ (Riccioli, 1651, pp. 85-870).

It was Huygens who deduced that for small arcs, the time of a single vibration (normally expressed in seconds) is $t=\pi \sqrt{ }(l / g)$, where $g$ is the acceleration due to gravitation, and $l$ is the distance between the point of suspension and the centre of the bob. In a manuscript dated January 1660, intended for the artisans who would make his clocks, he used the inverse of this relationship to obtain the first, remarkably accurate, estimate of the acceleration due to gravity as 31.25 [Rheinland] feet per second per second (9.8094 $\left.\mathrm{m} \mathrm{sec}{ }^{-2}\right)$ with a pendulum 9.5 pouces $(24.83 \mathrm{~cm})$ long which made 3600 doubleoscillations in one hour (Société Hollandaise des Sciences, 1888-1950, 17: 100-101). Huygens' 1658 pamphlet Horologium [The timepiece] mentions a clock in which "each simple vibration" of the pendulum whose length "is about five-sixths of a Rhenish foot" takes "half a second exactly", and his first 3-foot seconds pendulum clock was being built in November 1658 (Société Hollandaise des Sciences, 1888-1950, 2: 272). Interchange of ideas between Britain and the Netherlands at this time was spread by both by a constant flow of clockmakers in each direction (Leopold 1989), and exchange of correspondence. Huygens major treatise on the pendulum clock, Horologium osillatorium [The pendulum clock], was published in 1673 . However, his clock mechanism proved to have problems with its long-term regularity, and in 1680 a pendulum clock with an anchor-escapement was made by a London clockmaker, William Clement (Reid, 1830, p. 117). This was rapidly adopted in The Netherlands and Germany, and by 1695 was also in use in France. The pendulum clock now become an accurate time-keeper, and rapidly became established as an essential navigational aid.

Local clock-time could be checked against standard time at the Greenwich, Paris or at other observatories by observing the transit of a given star (i.e. its time of passage across 
the meridian, as it intersected the cross-wires of an observer's fixed telescope). Predicted transit dates and times for many stars were tabled by astronomers.

\section{A SURPRISING RESULT}

One of the ideas underlying the French government's creation of the Académie Royale des Sciences in 1666 had been to promote improved map-making, sailing charts, and the determination of longitude. Expeditions were dispatched overseas to use astronomical observations to better determine the location of various French possessions. One result of this activity was that careful weekly observations by Jean Richer (1630 1696) at Cayenne (French Guiana) over a period of ten months in 1672 found his astronomical clock to be loosing $2^{1} / 2$ minutes a day relative to Paris time, and its pendulum had to be shortened to correct this. When reported on Richer's return to France (Anonymous, 1674; Richer, 1729), this result was deemed so extraordinary that it was initially disbelieved, until a second expedition by three hydrographers, Messieurs Jean Varin, Jean Des Hayes (d. 1707) and Guillaume De Glos to Gorée (a small island off the west coast of Africa) and to Guadaloupe (French Lesser Antilles) in the West Indies in 1682, confirmed the same effect (Varin et al., 1729). However, considerable doubt remained as to whether the phenomenon was caused by some kind of observational error, or not.

\section{TOWARDS UNIVERSAL GRAVITATION}

In England, efforts to understand the nature of gravitational attraction had been made by Fellows of the Royal Society in the years prior to the publication of the first edition of the Philospohiae naturalis Principia mathematica [Mathematical Principles of Natural Philosophy] by Isaac Newton (1643-1727) in 1687. By analogy with magnetic attraction, it was surmised by many at this time that the weight of objects might change with their distance either above or below the surface of the Earth, and that the gravitational attraction towards the centre of the Earth might decrease. Henry Power (1623-1668) in November 1662, and Edward Cotton (c. 1616 - 1675) in June 1664, both experimented with weighing a brass weight at the surface of the Earth, using a pair of scales, and then lowering it on a thread down a mine-shaft to see if there was any change in its apparent weight at depth (Birch, 1756, pp. 133-134, 433). Power claimed that this was indeed the case.

The brilliant experimentalist, Robert Hooke (1635-1703), "curator of experiments" to the Royal Society, had read Riccioli's Almagestum novum [The new greatest astronomical compilation] in 1655 (Gunther 1930, p. 10), and had a keen interest in the history of the earth (Davies 1964, Oldroyd 1996). He investigated Power's findings with his own balance experiments, carried out from the tower of Westminster Cathedral in London in December 1662 and from the top of St Pauls Cathedral in August 1664, but both proved inconclusive (Hooke in Birch, 1756, 2, pp. 69-73; Inwood, 2002, pp. 49-50). In December 1664, Hooke reported to the Royal Society that he had determined the length of the seconds pendulum in London to be $3 \mathrm{ft} 1 \frac{2}{5}$ in $(0.95 \mathrm{~m})$ and postulated that if the "gravity of the Earth" behaved in a similar way to magnetic attraction, then "if so, the standard [measurement of time] by a pendulum will be uncertain, because a second pendulum toward the poles will be much longer than near the equator" (Birch, 1756, 1, p. 507). But this may well have been simply conjecture, as there was no understanding 
at this time of the laws governing gravitational attraction and Hooke does not seem to have been a sufficiently strong mathematician to have derived a theoretical solution to the problem. Never-the-less, he was a gifted inventor. In March 1666, he repeated the "weighing at depth" experiment, using a sensitive balance and shafts some sixty fathoms $(110 \mathrm{~m})$ deep in the Chalk at Banstead Downs, Surrey. This time, he definitely found no change of weight at depth. He suggested that perhaps timing thousands of oscillations of a "swing-clock" pendulum enclosed in an airtight case might provide a more sensitive measure. Alternatively, a spring-balance "carefully conveyed from place to place" might provide a means to measure the "differing weight" of a "weight of convenient bigness" in several places (Birch, 1756, 2, p. 72). Although it was ordered by the Society that such experiments should be carried out by Hooke, he seems to have become diverted by magnetic experiments. Despite having done much to develop the theory of the spring (Hooke 1678), there is no evidence that his proposed spring-balance (illustrated in Gunther, 1930, p. 259) was ever built and his suggestion had no influence on subsequent developments.

In 1686, Edmond Halley (1656-1742) visited the island of St. Helena to undertake Southern hemisphere astronomical observations (Cook, 1998, pp. 61-88). On arrival, he too found that in order for his clock to keep the same time as at Greenwich, the length of its pendulum needed to be shortened. Surprised by this, he wrote to Newton, reporting his finding. In fact, Newton had first begun consideration of his theory of universal gravitation in 1675 , and by 1680 had arrived at his, as yet unpublished, inverse-square law of gravitational attraction (Westfall, 1983, pp. 271, 387-388). Halley's observation resulted in Newton writing to him in July 1686 that the necessary shortening must be caused by a lessening of the intensity of gravity at St. Helena relative to that in London, hence the overall shape of the Earth could not be a sphere, as had hitherto been generally supposed.

In the Principia, Newton (1687, pp. 421-422) provided proof of this assertion. It had recently been established from astronomical observations that Jupiter had the shape of an oblate (grapefruit-shaped) spheroid. By analogy, Newton expected the Earth to behave similarly (Greenberg, 1996). He assumed that the Earth was homogeneous in composition and behaved as though it was entirely fluid, taking up the shape of the spheroid generated by the revolution of an ellipse about its minor axis, which he believed would be a stable form:

The equal gravitation of the parts on all sides would give a spherical figure to the planets, if it were not for their diurnal revolution in a circle. By that circular motion it comes to pass that the parts receding from the axis endeavour to ascend about the equator; and therefore if the matter is in a fluid state, by its ascent towards the equator it will enlarge the diameters there, and by its descent towards the poles it will shorten the axis. So the diameter of Jupiter (by the concurring observations of astronomers) is found shorter between pole and pole than from east to west (Newton 1726; translation: Cajori, 1934, p. 424).

He next considered the behaviour of columns of water in two hypothetical "canals", one of which extended from the surface at the (North) pole to the centre of the Earth and the other from the surface at the equator to the centre. Under the assumption of centrifugal force acting upon them, Newton (1687, pp. 424-426) deduced:

that the increase of weight in passing from the equator to the poles is nearly as [i.e. proportional to] the versed sine of double the latitude; or, which comes to the same thing, as the square of the sine of the latitude; and the arcs of the degrees of latitude in the meridian increase nearly in the same proportion. 
And, therefore .... the force of gravity at the pole is to the force of gravity at the equator as 230 to 229

[1.0044] (my emphasis; Newton 1726; translation: Cajori, 1934, p. 429)

i.e. $\operatorname{versin}(2 \theta) \equiv[1-\cos (2 \theta)] / 2=\left\{1-\left[1-2 \sin ^{2}(\theta)\right]\right\} / 2=\sin ^{2}(\theta)$, where $\theta$ is the latitude. He also noted (Newton 1687, p. 425) that "the lengths of pendulums vibrating in equal times are as the forces of gravity" (translation: Cajori 1934, p. 432).

Although the reports of the Richer and Varin expeditions did not appear in print for many years (Richer 1729; Varin et al. 1729), their findings soon became known following their return and clearly supported Halley's observation. The results of the pendulum observations at Cayenne, Gorée and Guadaloupe were referred to by Newton in the first edition of the Principia (Newton 1687, pp. 425-426). In the second (1713) and third (1726) editions, he updated the available data and included a table of the expected lengths of a one-second pendulum corresponding to various latitudes, as one progressed from the equator ( 3 [French] feet 7.468 lines; i.e. $99.13 \mathrm{~cm}$ ) to the pole ( 3 feet 9.387 lines; 99.63 cm) (Cajori 1934, unnumbered table p. 430), ascribing discrepancies between the observed and theoretical results to a variety of possible causes: observational error, "dissimilaritude of the internal parts of the Earth and the height of mountains" and, especially in tropical regions, air temperature (Cajori 1934, p. 432).

\section{THE LENGTH OF A DEGREE OF ARC}

Newton's results motivated much subsequent experimental work and further theoretical developments. At first, emphasis was simply on verification of his hypothesis, but with the passage of time, interest switched to estimation of The Figure of the Earth, i.e. obtaining improved estimates of the flattening (ellipticity) of the Earth's spheroid (see: Biot 1829, Airy 1845, Todhunter 1873, Clark 1877, Strasser 1957, Fisher 1975, Smith 1986 and Heilbron 1993 for discussion), a goal which was described (Sabine 1825, p. xii) as "the highest accomplishment of practical geometry."

Initial verification of Newton's conjecture could clearly be accomplished by physical measurement of the length of a degree of arc of latitude. The Royal Society had proposed this to Halley in 1686 (Westfall 1983, p. 453), but it was never carried out. However, as a basis for the proposed new mapping of France, in 1669, Jean Picard (1620 1682) triangulated an $\operatorname{arc}$ of $1^{\circ} 22^{\prime} 55^{\prime \prime}$ along a meridian from Malvoisine (near Paris), to Amiens, and astronomically determined the locations of the end-points. In 1683, work by Phillipe de Lahire (1640-1718), Giovanni Dominico Cassini (1625-1712) and his son Jaques Cassini (1677-1756) began on extending this transect northwards to Dunkirk (on the Normandy coast), and southwards to Collioure (on the Mediterranean coast). In the first edition of the Principia, Newton (1687, p. 424) used their measurement of the length of the $8^{\circ} 31^{\prime} 11.83^{\prime \prime}$ Collioure-Dunkirk arc to estimate the radius of a spherical Earth.

The very few pendulum observations which by then existed inconveniently appeared to support the Newtonian hypothesis of an oblate spheroid, but the French arc-length measurements suggested that the length of a degree of arc south of Paris was greater than one to the north of the city. This finding precipitated strong disagreement between supporters of the Cassinis and Newton as to what the correct Figure of the Earth actually was. The former favoured a (lemon-shaped) prolate spheroid and the latter an oblate spheroid. The pendulum observations were dismissed by the French as subject to gross observational error and therefore too inaccurate to be decisive. In August 1690, when the English Queen, Mary II (1662-1694) visited the Paris Observatory and mentioned, in the 
course of a discussion of the importance of improving measurement of longitude, that Newton and others in England thought the Earth was shaped like Jupiter, it was explained to her that the shadow of the Earth on the Moon during an eclipse showed its shape to be spherical, and that reports of the shortening of pendulum lengths in far-away places were to do with the nature (temperature) of the air since, at Paris, little difference was found between winter and summer (Anonymous 1690, pp. 101-102).

Eventually, it was agreed that only the actual measurement of the lengths of an equatorial and a polar degree of arc would be sufficient to end the controversy. Accordingly, the Académie Royale finally dispatched two expeditions, with this express aim (see Smith 1986 for a detailed account). The first set out to Peru in May 1735, under the direction of the mathematician-astronomers Pierre Bouguer(1698-1758) and Charles Marie de La Condamine (1701-1744); the second to Lapland in April 1736, under Pierre Louis Moreau de Maupertuis (1698-1759). The Arctic party returned first, in August 1737. Their results (Maupertuis 1738) conclusively showed that the one-degree northern arc length was considerably longer than that predicted by the Cassinis. Newton's model was thus completely vindicated.

\section{PENDULUM LENGTH AND THE FIGURE OF THE EARTH}

Proofs of Newton's conjecture, that an ellipsoid of revolution would be a stable form, were given by the Scottish mathematicians, James Stirling (1692-1770) in 1735 and Colin Maclaurin (1698-1746) in 1740, and by the French mathematician, Alexis Claude Clairaut (1713-1765) in 1737 (Todhunter 1873). Finally, an exhaustive theoretical analysis was published by Clairaut (1743). In this work (pp. 243-250), he showed that in the case of an elliptical body made up of a series of concentric shells with a common centre of rotation, but with each shell having a different ellipticity (flattening) and density, the difference in the intensity of gravity between the equator $\left(g_{\mathrm{e}}\right)$ and the pole $\left(g_{\mathrm{p}}\right)$ relative to that at the equator, $\left(g_{\mathrm{p}}-g_{\mathrm{e}}\right) / g_{\mathrm{e}}$ was equal to $5 k / 2-f$, where $(k)$ is the ratio of centrifugal force per unit mass at the equator (given by the product of the square of the angular velocity of rotation and the equatorial radius) to the mean value of gravity at the equator (this ratio was known from astronomical data to be equal to $1 / 289$ ), and $(f)$ is the flattening.

This was subsequently known as Clairaut's theorem (Biot 1829, p. 38; Todhunter 1873, p. I: 221) and was of great importance because, as Clairaut (1743, p. 251) pointed out, it enabled the flattening to be obtained from the shortening of the pendulum in proceeding from the pole to the equator. Biot (1829, pp. 37-38) and Airy (1845, p.231) restated his findings more clearly: the length of a seconds pendulum $(l)$ at latitude $\theta$ is:

$$
l=l_{e}\left(1+c \sin ^{2} \theta\right)
$$

where $l_{e}$ is the length at the equator and the constant $c=(5 k / 2-f)$. Hence, by fitting an equation

$$
l=a+b \sin ^{2} \theta
$$

to a set of pendulum-length data observed at various latitudes, the flattening is given by:

$$
f=0.00865-(b / a)
$$

By the late eighteenth century, sufficient numbers of observations of seconds pendulum length at various latitudes had begun to accumulate that new, essentially statistical, techniques began to be applied to fit the equation, $l=a+b \sin ^{2} \theta$, and hence find $f$.

In a book on applied mathematics, the German physicist, Johann Heinrich Lambert $(1728-1777)$, fitted the equation $l=439.087+2.559 \sin ^{2} \theta$ (Paris lines; $1 \mathrm{~m}=443.34$ lines) 


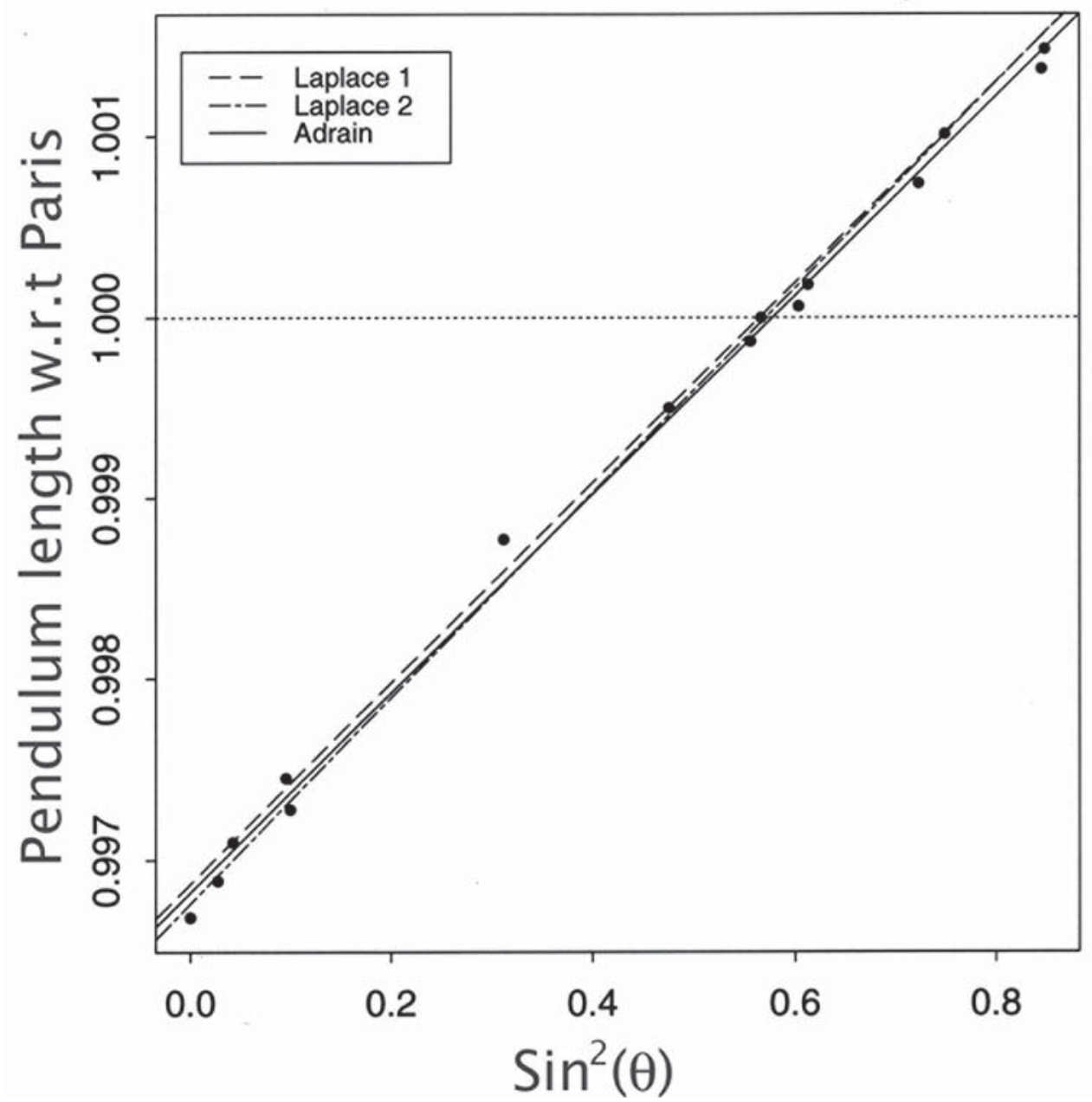

Figure 1. Laplace (1799, pp. 146-152) fitted equations to a set of 15 measurements of pendulum length, expressed in terms of the length in Paris by (1) minimising the magnitude of the largest residual and (2) by a modification of Boscovich's method (Maire and Boscovich 1770). The figure also shows the same data set fitted by the method of least-squares (Adrain 1818). Only tabular presentations of these results were used by the authors.

to a set of 11 observations (Lambert 1765, pp. 455-456). He accomplished this by dividing the individual equations into two nearly equal-sized groups, gathering the smaller observations of $l$ in one, the larger in the other and calculating the equation of the line through the bivariate means of the two groups. He obtained $f=1 / 332$. His approach was very similar to a method introduced by the German astronomer and mathematician, Johann Tobias Mayer in 1750 (but which simply summed the coefficients in each group) and it continued to be used under the name "Meyer's method" well into the nineteenth century (e.g. Airy 1845).

However, the importance of such data analysis only began to be generally realised when the French mathematician Pierre Simon, Marquis de Laplace (1749-1827) fitted equations to a set of 15 measurements of pendulum length in his Traité de Méchanique Céleste [Treatise on celestial mechanics] (Figure 1; Laplace 1799, pp. 146-152) by: (i) 
minimising the magnitude of the largest residual and (ii) by a modification of a method which the Croatian mathematician, Ruggerio Guisseppe Boscovich [Rudjer Josef Boskovic] (1711-1787), had applied to measurements of a one degree arc-length from various latitudes (Maire and Boscovich 1770), arriving at $f=1 / 321$ and $1 / 336$ respectively.

With the independent discovery of the "method of least-squares" by the French mathematician Adrien Marie Legendre (1752-1833), the Irish-American mathematician Robert Adrain (1775-1843) and the German astronomer and mathematician, Carl Friedrich Gauss (1777-1855), published in 1805, 1808 and 1809 respectively (although Adrain's work passed unnoticed), a rigorous method for fitting equations to such data became established (see: Stigler 1986, Hald 1998, or Howarth 2001 for discussion).

\section{PENDULUM MEASUREMENTS}

There were two types of measurements made of the intensity of gravity. The first measured $g$ (in terms of the length of a pendulum beating seconds) at a primary observation site, usually a national observatory. The second made relative measurements, which could be calibrated by using the same instrument, to determine $g$ at a secondary station.

\section{Paris 1792}

A classic example of the care with which a determination of the length of a seconds pendulum was made is the work carried out at the Paris Observatory in June and August 1792, as part of the establishment of the metric system in France (Débarbat and Ten 1993), by the mathematician and astronomer, Jean Charles de Borda (1733-1799) and its director, the mathematician and geographer, Jacques-Dominique Cassini de Thury (1748-1845).

They used what they called the method of coincidences (Borda and Cassini de Thury 1810) to determine the number of oscillations made by a compound pendulum in a given time, an improvement of a technique introduced in 1735 by their fellow-countryman, the mathematician and astronomer Jean-Jacques D'Ortus de Mairan (1678-1771) (Mairan 1738). In their experimental arrangement, using apparatus designed by Borda, the platinum bob of the trial pendulum was suspended at the end of a fine steel wire $(c .4 \mathrm{~m}$ long) anchored via a knife edge from a bracket securely fixed to a wall in the Observatory. This "simple" trial pendulum swung in front of a clock pendulum which beat seconds (Figure 2). A small cross of white lines on a black background was painted the centre of the bob of the clock. The apparatus was enclosed in a glass case (not shown in Figure 2) to reduce the effects of draughts. At the instants of coincidence, both pendulums would move through the midpoint of their swings at the same time and an iron wire at the base of the pendulum bob would pass in front of the centre of the cross on the clock bob. The moment of coincidence was observed from a distance (a telescope being used for greater accuracy) and the time noted. The two pendulum lengths were chosen such that the trial pendulum would make a little less than one complete oscillation while the clock made two.

In the first of four daily trials, they found the interval between the first and second coincidences to be $73 \mathrm{~m} 14$ s, i.e. 4394 s. During this time, the clock had gained two seconds on the pendulum, so the number of oscillations made by the trial pendulum in this time was $(4394-2) / 2=2196$. 


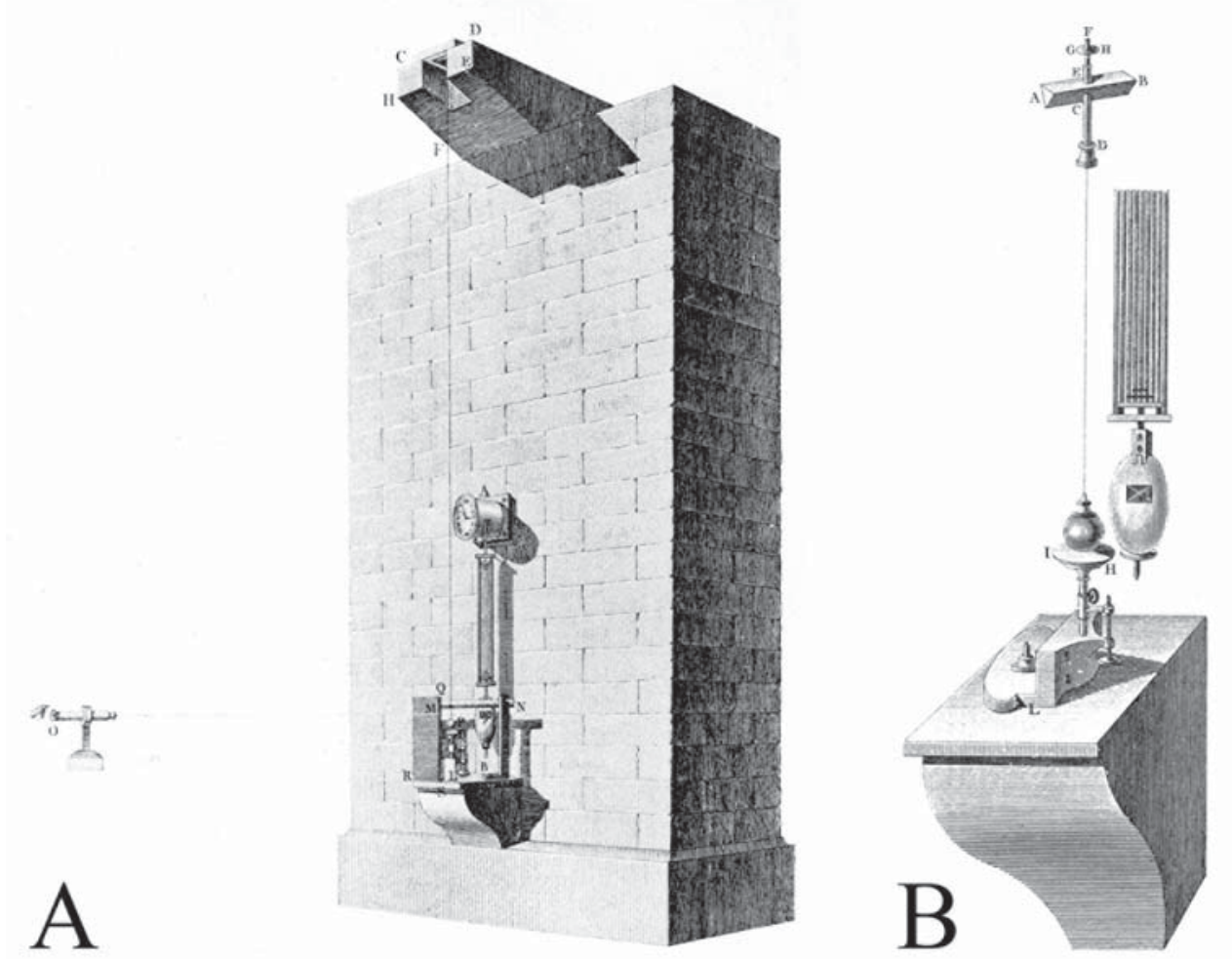

Figure 2. Apparatus used in Borda and Cassini de Thury's experiment to determine the length of the seconds pendulum at the Paris Observatory in 1792. (A) General view of the apparatus and observer's station (Wolf, 1889a, IV: Pl. II); (B) enlarged view of the temperature-compensating gridiron clock pendulum (note the cross marked on it), the "simple" trial pendulum and its bob. (Wolf, 1889a, IV: Pl. III, Figs. 2 and 3).

As noted earlier, the mean solar day (MSD) is, by definition, $86400 \mathrm{~s}$ long. In the interval between one transit of a chosen star and its second sighting approximately 24 hours later, it was found that the clock gained $13.4 \mathrm{~s}$, so the actual number of oscillations made by the clock during a sidereal day (the time it takes for a distant "fixed" star to return to the same point in the sky each night) was $(86400+13.4)=86413.4$ s. Hence, the clock will make

$$
86413.4 x(86164 / 86400)=86650 \text { oscillations per MSD. }
$$

The corresponding number made by the trial pendulum is:

$(86650 \times 2196) / 4394=43305.28$ oscillations.

The average of four repeated sets of measurements in one day was 43305.30 oscillations. As large oscillations proceed more slowly than small ones, this figure was then corrected (Bernoulli 1750) to obtain the equivalent number of oscillations (43305.48) which would have been made had the arcs been of infinitely small amplitude.

The measured length of the trial pendulum was 202965.82 divisions of a platinum ruler over 12 Paris feet $(3.9 \mathrm{~m})$ long; each scale division being 1/100 000 of the toise of Peru $(1 \mathrm{t}=864$ Paris lines $(\mathrm{Pl}) \equiv 1.949 \mathrm{~m})$. If two simple pendulums are acting under the same forces, and oscillate in similar arcs, then their lengths $\left(l_{1}, l_{2}\right)$ are reciprocally proportional to the ratio of the squares of the number of oscillations they make in the same time $\left(N_{1}, N_{2}\right)$. Hence the length of the equivalent seconds pendulum is: 


$$
l_{2}=l_{1}\left(N_{1}\right)^{2} /\left(N_{2}\right)^{2}
$$

\section{i.e. $202965.82(43305.48)^{2} /(86400)^{2}=50989.55$ divisions}

Further corrections, for effects of the buoyancy of the air (reduction to a vacuum, Bouguer 1749, pp. 341-342); temperature; extension of the suspension wire because of the mass of the bob and pendulum swing; and the expansion of the ruler under its own weight; increased this to 50999.75 divisions.

The mean of all twenty sets of experiments gave 50999.60 divisions, equivalent to $50999.6 \times 864 / 100000=440.63654 \mathrm{Pl}$. The final result, taking into account differences between the ruler used in the experiment and four rulers previously constructed as a basis for the metric system (Débarbat and Ten 1993) established the standard length for a onesecond pendulum at the Paris observatory (48 $50^{\prime} 11^{\prime \prime}$ latitude) reduced to sea level (Bouguer 1749, pp. 357-364) as 440.5593 Pl (0.9938 m).

The following year, the metre was provisionally adopted by the National Convention as the new unit of measure, by definition 1/10 000000 of the distance between the pole and the equator. It equalled 443.44 Pl, revised in 1799 to $443.296 \mathrm{Pl}$ (Débarbat and Ten 1993).

\section{Kater's convertible compound pendulum}

In 1816, the British House of Commons was petitioned to begin a programme of measurements of the length of the seconds pendulum in London and at the principal stations of the Ordnance Survey through Great Britain. The petition was granted, and the Royal Society was requested to assist with the implementation of the programme. In 1817, Capt. Henry Kater (1777-1835), a retired English officer from the British army in India, with experience in survey work, and a member of the committee, designed and constructed the first convertible pendulum (Figure 3A). A convertible compound pendulum is one which has two knife edges at different distances from its centre of gravity. Huygens (1661) had given a theoretical proof that a compound pendulum would have conjugate points on either side of its centre of gravity which have the same periods of oscillation. Taking either of these points as the centre of suspension, the other will be the centre of oscillation, and the distance between these two points will be the length of the equivalent simple pendulum. Although the French mathematician and engineer, Baron Gaspard-Clair-François-Marie Riche-de Prony (1755-1839) presented a paper to the Institut de France in 1801 on the design for a pendulum on the same principal, it was not published in his lifetime. Kater's design and experimental procedure was based solely on his awareness of Huygen's theorem. In June and July 1817, Kater made a series of 12 trials at the house of Henry Browne, in Portland Place, London, using the method of coincidences (Figure 3B), in each of which the number of vibrations in 24 hours was determined with the trial pendulum first inverted, with the bob above, then with it below. In both cases, the position of the two small weights (Figure 3A) was adjusted to obtain as similar numbers of vibrations in $24 \mathrm{~h}$ as possible. Kater's observations were extremely repeatable, differing by less than 0.1 vibration in 86058 between the mean "above" and "below" pairs of results (Kater 1818, p. 86) and he found the length of the seconds pendulum, after the usual corrections, to be 39.1386 in, later revised (Kater 1819, pp. $414-415)$ to 39.13929 in $(99.414 \mathrm{~cm})$. 


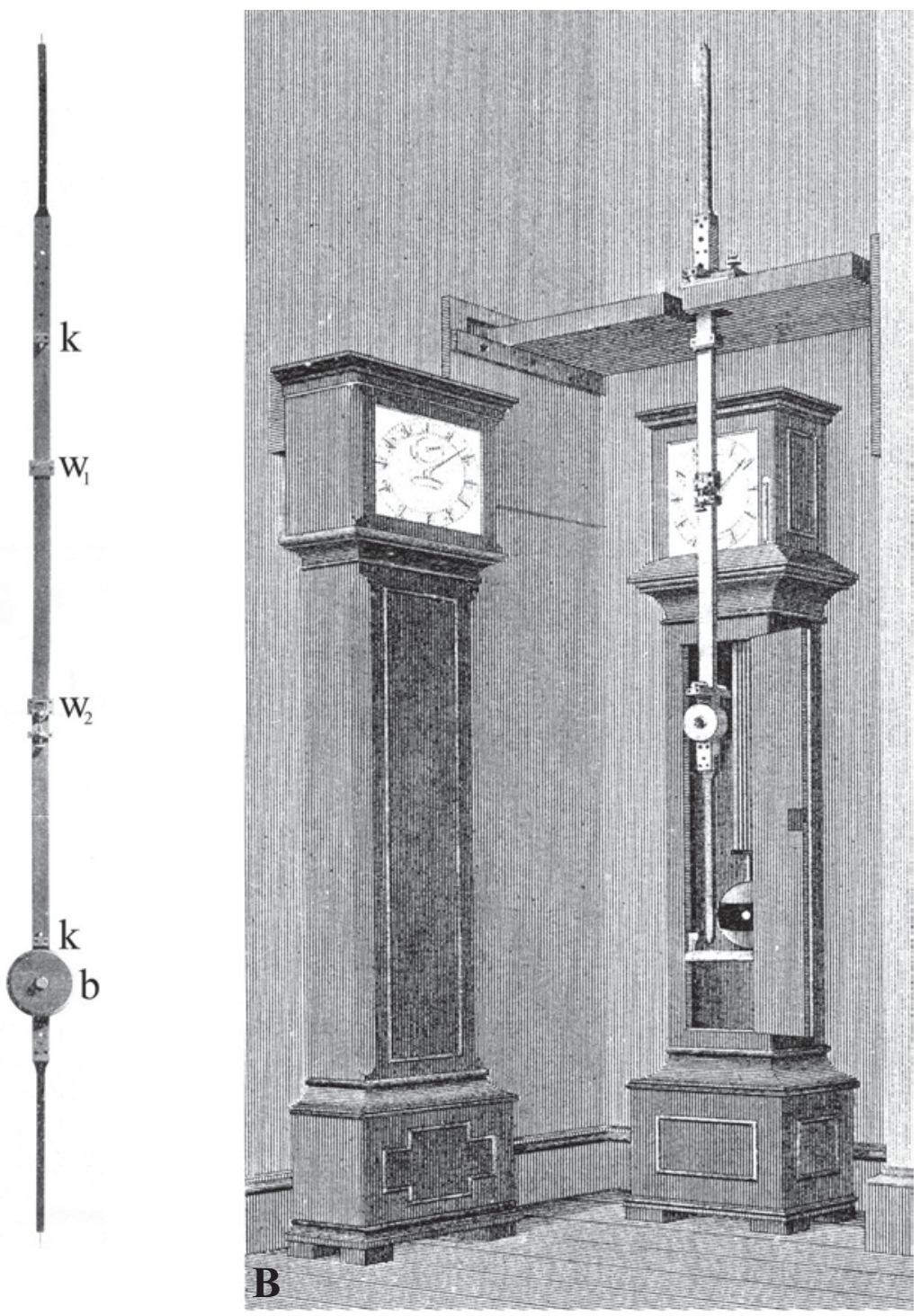

Figure 3A. Kater's convertible compound pendulum, made of a brass bar $1.5 \mathrm{in}(3.81 \mathrm{~cm})$ wide and $1 / 8$ in $(0.32 \mathrm{~cm})$ thick, used to find the length of the seconds pendulum in London in 1817: b, the fixed bob $(1.11 \mathrm{~kg})$; $k$, $k$, two inward-facing holes, 39.4 in (100 cm) apart, to admit triangular steel knife edges; $w_{1}$, sliding weight $(213 \mathrm{~g})$, fixed at $\mathrm{c.} 13 \mathrm{~cm}$ from the point of suspension by tightening two screws on the weight; $w_{2}$, weight (113 g) c. $4 \mathrm{~cm}$ from the centre of the pendulum, adjustable by sliding over a short scale with $1 / 20$ in $(1.27 \mathrm{~mm})$ divisions. The narrow extensions, $17 \mathrm{in}(43 \mathrm{~cm})$ long, at top and bottom of the bar, are made of deal, painted black (for ease of comparison with the spot pained on the bob of the clock) and tipped with a whalebone pointer (Wolf, 1889a, IV: Pl. IV, Fig. 1).

Figure 3B. The experimental apparatus. Note the use of the temperature-compensating gridiron pendulum for the trial clock. The observer's telescope is not shown. The second clock (left) was used as the standard of comparison with astronomical time (Wolf, 1889a, IV: Pl. V). 


\section{The invariable pendulum}

Meanwhile, linkage between studies in France and the British Isles had begun through the work of the French physicist and mathematician Jean-Baptiste Biot (17741862), who had already determined the length of the seconds pendulum at Formentera, Spain, in France at Figeac, Bordeaux, Clermont and Paris (Biot 1818a), using the same method as had Borda and Cassini de Thury in 1792, but with the "simple" pendulum reduced in length from 12 French feet to somewhat less than 3, in order to make use of the apparatus in the field easier. In May 1817, Biot came to Britain where, accompanied by staff of the Ordnance Survey, he determined the length of the seconds pendulum at Leith Fort (Edinburgh) and on Unst in the Shetland Isles, Scotland, and at Greenwich Observatory, London (Biot 1818b, pp. 49-50).

The following year, Kater (1819) undertook measurements at all the Ordnance Survey base stations: Unst, Portsoy, Leith Fort, Clifton, Arbury Hill (Northamptonshire), London and Dunnose (Isle of Wight). In order to accomplish this, he made an invariable compound pendulum, modelled after his convertible pendulum. It consisted of a solid brass bar $5 \mathrm{ft}(152 \mathrm{~cm})$ long, 1.6 in $(4 \mathrm{~cm})$ wide and 0.125 in $(0.3 \mathrm{~cm})$ thick, with a flat circular sliding weight soldered to the bar in such a position that the trial pendulum would make two vibrations less than the clock in 8 or 9 minutes. Below the weight, the bar was reduced to 0.7 in width and painted black for easy comparison with a sighting spot on the bob of the clock pendulum. The trial pendulum swung from steel knife edges resting on agate planes embedded in the top surface of a levelled, massive, iron frame.

In both Biot's and Kater's field trials, the length of the pendulum was fixed, other than temperature-related expansion or contraction (and this could be calculated from the temperature attained by a nearby thermometer). All that was necessary was to count the number of vibrations made in 24 hours; clock-time being checked by frequent observations of astronomical transits. Calibration of the entire apparatus was made by first swinging it at the primary station (Paris or London). Thereafter, the seconds pendulum length at any other place $\left(l_{2}\right)$ could be obtained, as above, from the relation

$$
l_{2}=l_{1}\left(N_{1}\right)^{2} /\left(N_{2}\right)^{2}
$$

where $l_{1}$ and $l_{2}$ are the lengths (here corrected to a standard temperature of $70^{\circ} \mathrm{F}\left(21^{\circ} \mathrm{C}\right)$ and for the height of the station with respect to sea level), at the base station and field locality; and $N_{1}$ and $N_{2}$ are the corresponding mean number of oscillations (reduced to an indefinitely small arc and corrected for bouyancy of the atmosphere) made under the same conditions in the mean solar day.

Given $l_{2}$, the intensity of gravity at that location could be found. The flattening could also be obtained from the results from any pair of stations whose latitudes were known: If $l_{1}$ is the length of the seconds pendulum at latitude $\theta_{1} ; l_{2}$ is the length at $\theta_{2} ; l_{\mathrm{e}}$ is the length at the Equator; and $d$ is the difference between the lengths at the Equator and the Pole, then

$$
\begin{gathered}
l_{1}-l_{2}=d\left(\sin ^{2} \theta_{1}-\sin ^{2} \theta_{2}\right) \text { hence } \\
d=\left(l_{1}-l_{2}\right) /\left\{\sin \left(\theta_{1}+\theta_{2}\right) \sin \left(\theta_{1}-\theta_{2}\right)\right\} \text { and } \\
l_{\mathrm{e}}=l_{1}-d \sin ^{2} \theta_{1}
\end{gathered}
$$

then, from Clairaut's theorem, the flattening $f=0.00865-(d / l)$. As a result of this improvement in pendulum technology and application of the theory, a practical tool for investigating the Earth's gravitational field had developed.

Unfortunately, depending on which pairs of stations Kater considered, he found that he had a very large variety in values of flattening, ranging from $1 / 230$ to $1 / 598$. The results therefore proved inconclusive, although the largest separation, Unst to London, gave 
$1 / 323$. He noted that many of anomalous values involved pairing with Arbury Hill and he conjectured

that the sudden increase of gravitation .... may be occasioned by a rock of primitive formation, approaching the surface of the earth in the vicinity of that station .... on consulting [William] Smith's Geological Map of England, it appears that Mount Sorrel, a mass of granite, is situated, together with other rocks of primitive formation, about 30 miles to the north of Arbury Hill (Kater 1819, p. 425; he is probably referring here to Smith's 1815 map, the first of its kind to be published).

Once again, a geological cause was suspected as the source of a discrepant result.

The period of major growth in the numbers of geographical exploring expeditions had begun, and would reach its peak around 1900. It had been recognised in France and England, that it was now desirable to extend the reach of observing stations to the highest possible latitudes in both northern and southern hemispheres (Hall 1976). A total of 13 invariable pendulums were made to Kater's design and in the next few years they came to be used around the world.

\section{Pendulum networks begin}

Following active service in the Royal Artillery in England, Gibraltar and Canada, Capt. Edward Sabine (1788 - 1883) returned to England in August 1816. On the strength of his reputation as a skilful observer, he was elected a Fellow of the Royal Society in 1818 and appointed by its Council as astronomer to the expeditions in search of the North-West Passage under Capt. John Ross (177-1856). Using two of Kater's invariable pendulums, he measured the length of the seconds pendulum at Hare Island in 1818 and Melville Island in 1820 (Sabine 1821). At the same time, the French navigator and hydrographer, Louis Claude Desaules de Freycinet (1779-1842) was swinging invariable pendulums of French design at Paris, Rio de Janeiro, the Cape of Good Hope, the Isle de France (SaintBarthélemy), Rawak, Guam, the Sandwich Isles, Port Jackson (New South Wales, Australia) and the Falkland Islands (Freycinet 1826).

The French had always preferred the use of detached pendulums (i.e. unconnected with machinery of any sort to maintain or regulate their oscillations) whereas, on Sabine's Arctic voyages, a committee of the Royal Society had decided that he should use two attached pendulums (so-called because they were each attached to the machinery of a clock, which counteracted their natural tendency to come to rest as a result of the resistance of the air, but their usage was otherwise identical to that of detached pendulums). However, this had apparently given rise to some criticism (Sabine 1825, pp. 274-275) consequently, when Sabine set forth to measure the length of the seconds pendulum at Sierra Leone, St. Thomas, Ascension, Bahia, Maranham, Trinidad, Jamaica, New York, Hammerfest, Spitzbergen, Greenland and Trondhjem between February 1822 and October 1823, he took with him four of Kater's invariable pendulums: two detached and two attached, for the purpose of comparison (Sabine 1825, pp. 3, 327).

His observations occupied a total of 482 days during the voyage and the repeatability of his results was excellent. Analysis of his tabular data (which he had corrected for local variations in temperature, air pressure, station height, etc.) shows that despite large variations in temperature (c. $30^{\circ}$ to $90^{\circ} \mathrm{F} ;-1^{\circ}$ to $32^{\circ} \mathrm{C}$ ) and barometric pressure (c. 29 to $31 \mathrm{in} ; 74$ to $79 \mathrm{~cm})$, the errors in the recorded number of vibrations per $24 \mathrm{~h}$ rarely exceeded one vibration with respect to the station means (Figure 4) and supports his conclusion (Sabine 1825, f.n. p. 284) that the detached pendulums performed better. He 


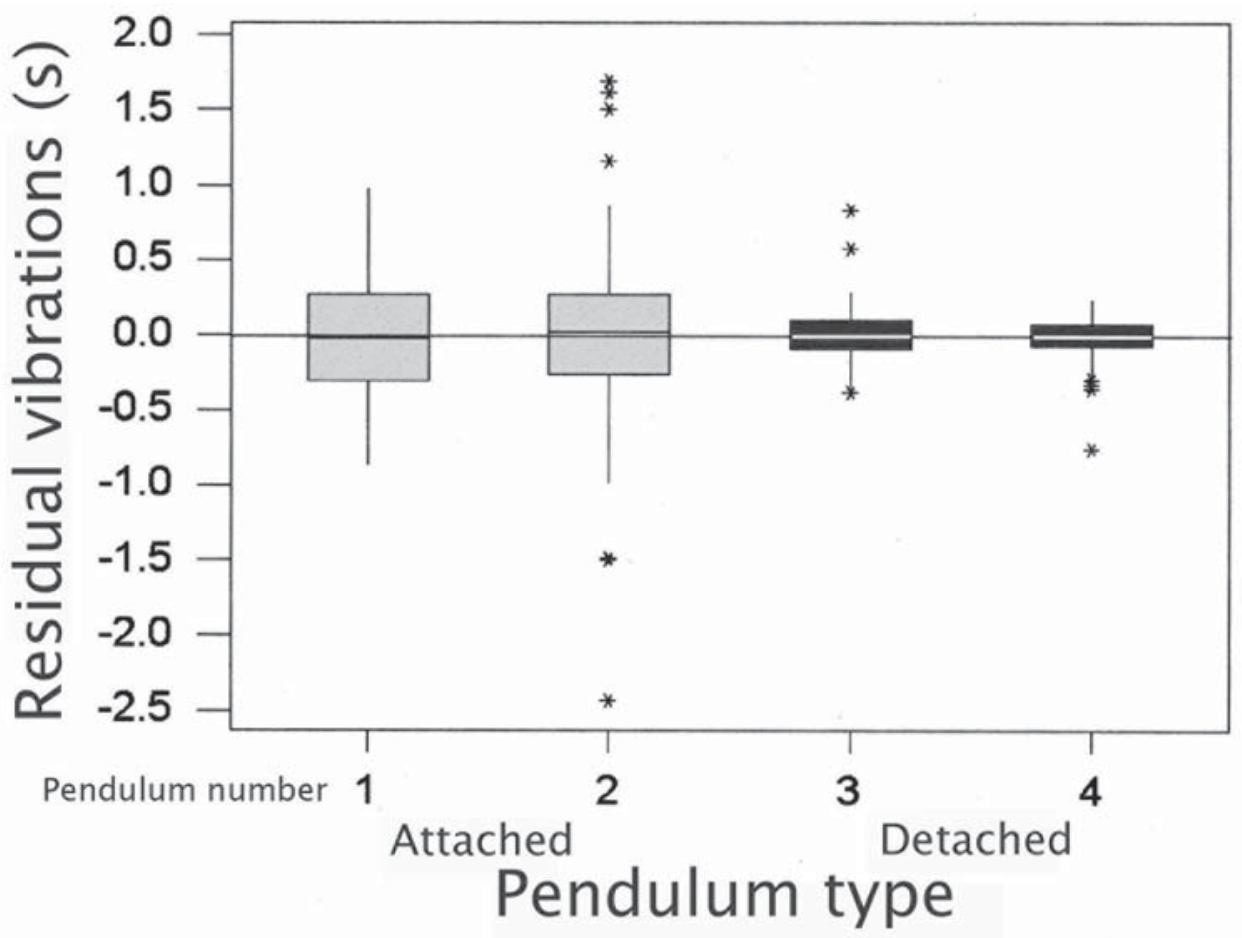

Figure 4. Boxplots showing the precision of Sabine's pendulum observations on his 1822-23 expedition. $n=$ 482 days. Two detached pendulums (unconnected with machinery of any sort to maintain or regulate their oscillations); and two attached pendulums (attached to the machinery of a clock to counteracts their natural tendancy to come to rest as a result of the resistance of the air) were used. Measurements were made at: Sierra Leone, St. Thomas, Ascension, Bahia, Maranham, Trinidad, Jamaica, New York, Hammerfest, Spitzbergen, Greenland and Trondhjem (see Sabine (1825) for the original counts of vibrations per $24 \mathrm{~h}$ ). The errors in his measurements have been combined by subtracting the respective means for each pendulum at each station from their corresponding observations. (The overall mean was 86210 vibrations per $24 \mathrm{~h}$ ). The boxes enclose the central $50 \%$ of the data, asterisks show outliers, whiskers indicate the range of the rest of the observations. The median (centreline of the box) coincides with the line drawn through zero in all but one case. As Sabine found, the precision of the detached pendulums is better.

attributed the occurrence of larger errors in the attached pendulum results to "accidental and temporary affections of the action of the weight, in its transmission to the pendulum, through the machinery of the clock" Sabine (1825, p. 279).

In his analysis of the results, Sabine (1825, pp. 329-372) fitted the equation

$$
l=39.01568+0.20213 \sin ^{2} \theta \text { in }
$$

to the mean lengths of the pair of detached pendulums at each station, corrected for elevation above sea level, using Mayer's (1750) method, and found the overall flattening to be $1 / 288.4$.

He noted that the magnitude of "excess or defect in vibrations" (regression residual) for each station, which ranged from -4.12 vibrations per $24 \mathrm{~h}$ at Trinidad to +5.58 at St. Thomas, was greatly in excess of what might be expected from the repeatability of the experimental results. He concluded that it must therefore be related to the density of the "strata situated immediately beneath the pendulums" (Sabine 1825, p. 338) and that this apparent sensitivity of the pendulum to the nature of the substratum rendered it "an instrument of possible utility in inquiries of a purely geological nature" (p. 341). Gravity determinations were now being seen as providing a potential geological tool. 


\section{More corrections}

Interest in obtaining ever-more precise determinations of the length of the seconds pendulum led to both additional theory and improvements to pendulum design.

When determining the length of the seconds pendulum at Königsberg (Kaliningrad, Russia), the German astronomer and mathematician, Friedrich Wilhelm Bessel (17841846), used a "simple" pendulum, but introduced corrections for the stiffness of the suspension wire and the lack of rigidity of the connection between the bob and wire. Most importantly, he improved the correction (based on hydrostatic theory) for the bouyancy of the air through which the pendulum swung, used to convert the number of vibrations in air to the equivalent as if swinging in a vacuum. Bessel (1828) proved that it was necessary to take the inertia of the air into account, and introduced a constant $(n)$ by which previously corrected data should be multiplied to fully correct them.

As soon as notice of Bessel's improvement reached London, the Board of Longitude had a large vacuum chamber constructed and Sabine put the new theory to the test by swinging one of Kater's invariable pendulums in atmospheres of air and hydrogen at both atmospheric and reduced pressure. Disconcertingly, Sabine (1829) found that as Bessel had used a "simple" pendulum, a different value of $n$ was required with a compound pendulum, such as Kater's, even when swinging in air, but of more concern was the fact that the magnitude of $n$ also appeared to be influenced by some additional, unknown, factor.

The English astronomer, Francis Baily (1774-1844) then built his own vacuum chamber and investigated the behaviour of 42 different pendulum constructions. More alarmingly still, he found (Baily 1832) that not only did the value of $n$ vary with the overall shape of a pendulum but, most unexpectedly, even if the pendulum was simply a plain cylindrical rod (bar) hung from a knife edge, $n$ changed with its diameter. Thus, $n$ seemed to vary with the figure of a pendulum in a wholly unpredictable manner.

Seeking a cause for these unwelcome phenomena caused a flurry of activity among the best mathematical minds in Europe. Eventually, the Irish mathematician and physicist, Sir George Gabriel Stokes (1819-1903) provided a solution in 1856, based on the theory of the friction of fluids, which gave values of $n$ in agreement with experimental results.

\section{New designs}

Prior to Bessel's death in 1846, he had designed a completely symmetrical, reversible, rod-like compound pendulum with interchangeable knife edges. In a posthumous publication (Bessel 1849), he showed that if the figure of a pendulum is completely symmetrical, the moment of inertia of the displaced air is exactly the same in its two positions, so it will have no effect on the period, thereby rendering earlier corrections unnecessary. In 1862, the newly-established Schweizerische Geodätische Komission [Swiss Geodetic Commission] had a pendulum constructed to Bessel's design by a firm of Hamburg scientific instrument makers, under the direction of Georg (1804-1885) and Adolf (1806-1871) Repsold, sons of the German astronomer, Johann Georg Repsold (1770-1830) who had made apparatus for Bessel in the 1820s. Known as the RepsoldBessel reversible pendulum (Figure 5), it was short enough (c. $56 \mathrm{~cm}$ between the knife edges) to have a period of about $3 / 4$ S. The Swiss astronomer, Emil Plantamour (18151882) used it in 1865 to determine the length of the seconds pendulum at Geneva (Plantamour 1866). In 1898, the German mathematician, Philipp Furtwängler (1869- 


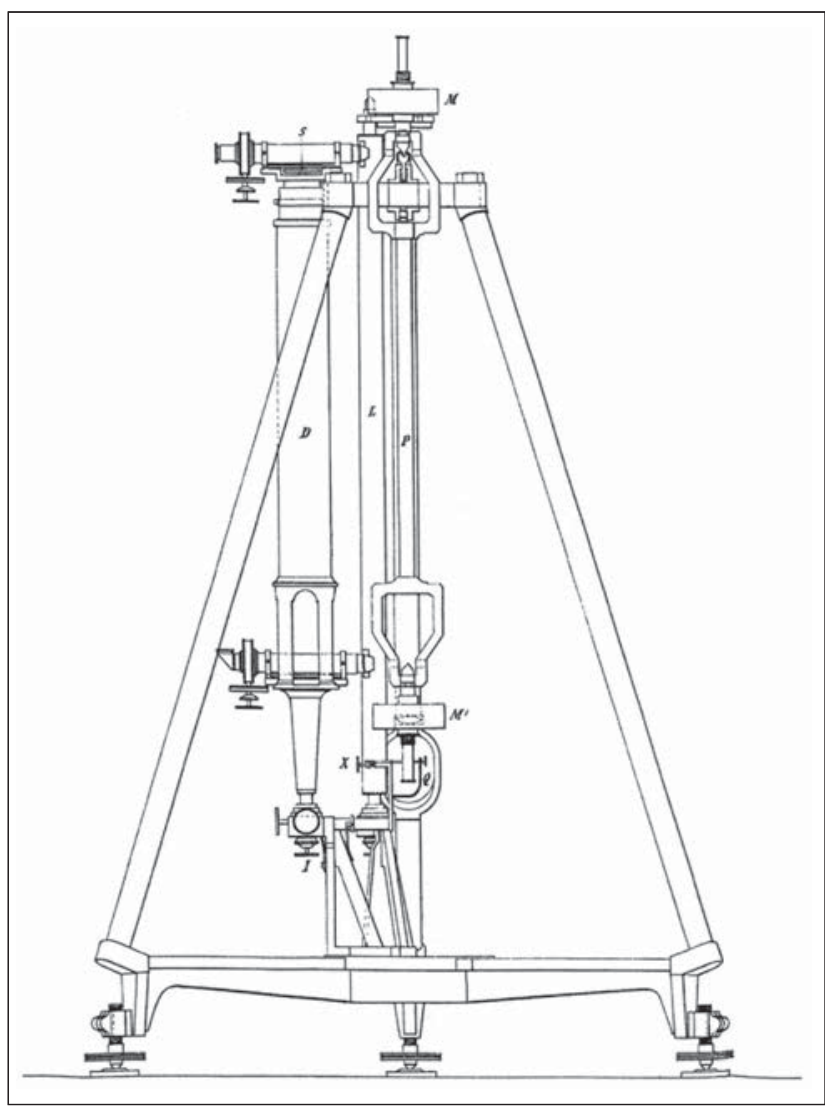

Figure 5. Front view of the RepsoldBessel reversible pendulum $(P)$ mounted on a heavy tripod stand; $M$, $M$ ' are the two symmetrical weights, the two triangular inward-facing knife edges can be seen in their supports lying just inside of these. To the left (mounted on D) are two microscopes(the upper one marked s) used to measure the distance between the knife edges (Plantamour 1866, Pl. I, Fig. I).

1940) and Friedrich Kühnen (1882-1940) used pendulums of the Repsold-Bessel type to make their definitive determination of $g\left(981.274 \pm 0.003 \mathrm{~cm} \mathrm{~s}^{-2}\right)$ at the Königlichen Preuszischen Geodätischen Institutes [Royal Prussian Geodetic Institute] in Potsdam (Kühnen and Furtwängler 1906). Their investigation was so painstaking that it established Potsdam as the world base for the absolute value of the intensity of gravity thereafter.

With the establishment of an international organisation, Die Mittel-Europäische Gradmessung [The Central European Arc Measurement], in 1864 to coordinate the work of the various European geodetic surveys, the reversible pendulum was adopted in central Europe, Switzerland and Russia, and thereafter in India and America. However, towards the end of the century, the complexity of its use brought invariable pendulums back into favour. Typical of these was a portable invariable $1 / 2 \mathrm{~S}$ pendulum (Figure $6 \mathrm{~A}$ ) introduced by an Austrian military officer, Maj. Robert (Freiherr von Daublebsky) von Sterneck (1839-1910) in 1885. It enabled stations to be established in a very short time and at low cost and by 1920 most of the countries in the world undertaking geodetic operations were using that type of pendulum (Bowie 1920, p. 551). In the United States, additional models were introduced by the astronomer, Charles Sanders Pierce (1839-1914); the physicist, Thomas Corwin Mendenhall (1841-1924) and others (Lenzen and Multhauf 1965).

By 1875, doubts were being raised by the Prussian General, Johan Jacob Baeyer (1794-1885), a former pupil of Bessel (quoted in Pierce 1883a, p. 359), and by Pierce in the following year (Hilgard 1883, Pierce 1883a), about errors caused by the flexure of the 


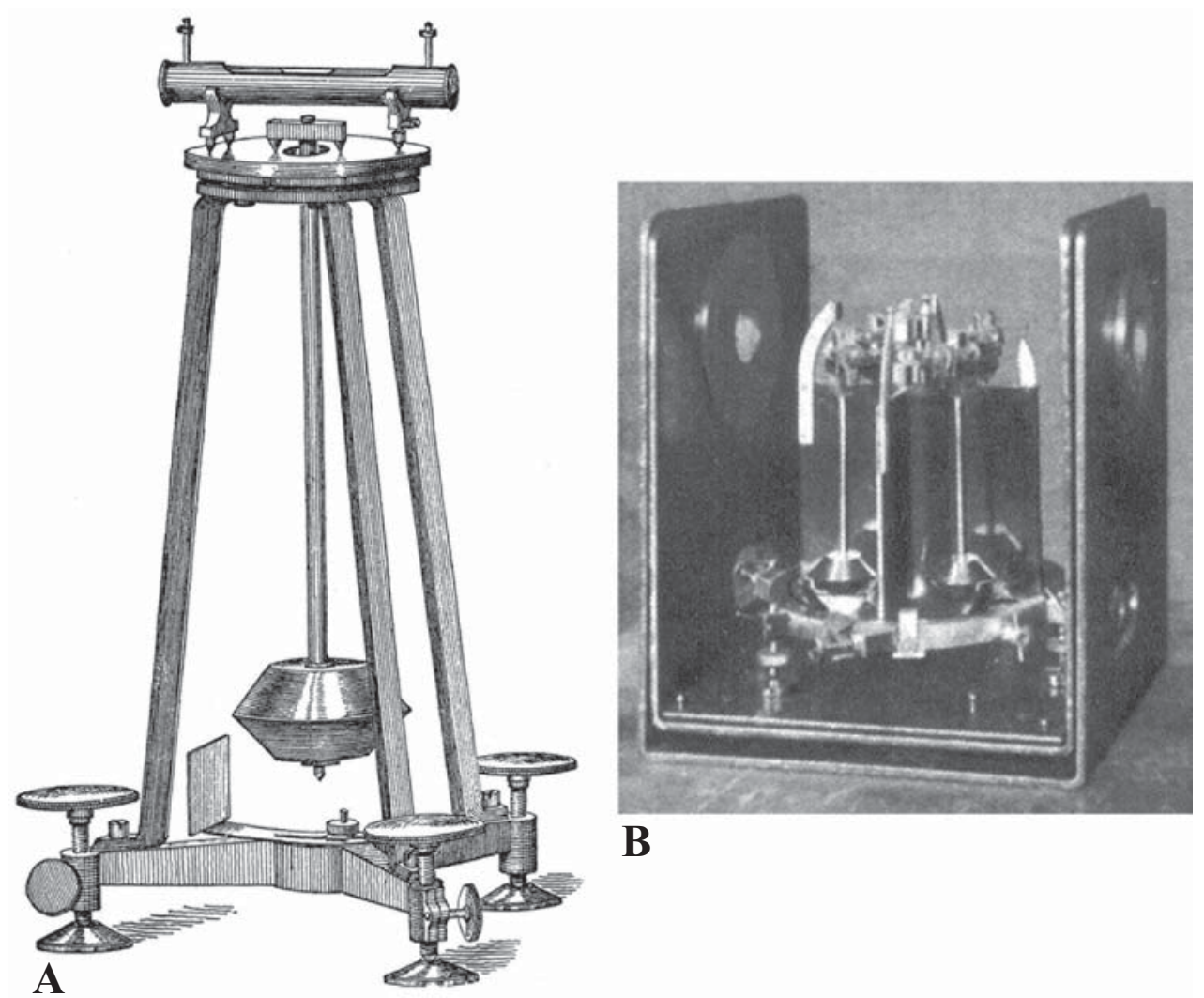

Figure 6. (A) von Sterneck $1 / 2$ s invariable pendulum, introduced in 1885. Thermometer and enclosing vacuum chamber not shown. The tail of the pendulum passed in front of a scale and was observed through a telescope. Coincidences occurred when the tail appeared in the middle of its swing, as seen through a pair of electricallycontrolled slits in the observing telescope; these slits, under the control of a chronometer, simultaneously opened every half-second (Poynting 1894, unnumbered fig. p. 31). (B) Four-pendulum arrangement used for gravity observations in submarines (Vening Meinesz 1925, Fig 2)

stands from which pendulums were swung. Although controversial, especially where the Repsold-Bessel pendulum was concerned, this phenomenon was subsequently confirmed by other observers (Sherman 1882, Schott 1883) (Figure 7). Based on a theoretical analysis, the French astronomer, Hervé Auguste Étienne Albans Faye (1814-1902) suggested, at a meeting of what had by then become Die Europäische Gradmessung [The European Arc Measurement], in 1877 (Bruhns and Hirsch 1878), that the use of two identical pendulums oscillating with equal amplitudes but in opposite phase could overcome such problems. However, nothing much came of this until Pierce (1883b) made the same recommendation, but this time backed-up by experimental evidence. A fourpendulum von Sterneck apparatus (Figure 6B) was eventually adopted by the Dutch geophysicist, Felix Andries Vening Meinesz (1887 - 1966), initially for work on land but subsequently for submarine-based marine gravity surveys (Vening Meinesz 1923, 1925). An alternative approach was to improve measurement of stand flexure, so that it could be corrected for. This was accomplished by the U.S. Coast and Geodetic Survey using optical interferometry (Burger 1911) and the method saw extensive field use (Swick 1931). 


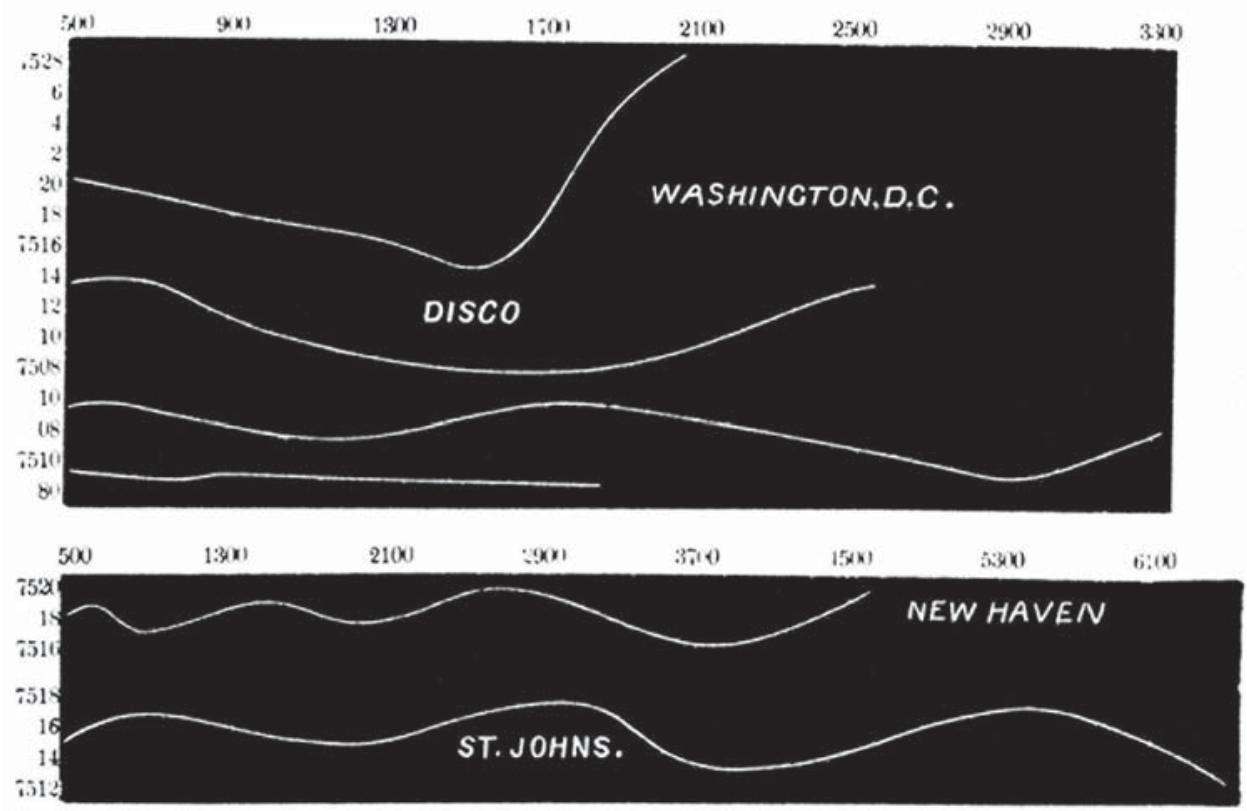

Figure 7. Variation of the mean time of vibration (s; ordinate) of a bar pendulum (Baily 1832) made to beat $i^{3} / 4 \mathrm{~s}$ at Washington DC, as a result of motion of the plane of suspension, and therefore of the stand. Abscissa is number of astronomical transits (time). Curves are drawn for the locations: Washington DC (the base station); Disco Is., Greenland (3 curves); New Haven, Connecticut; and St. Johns, Newfoundland. (Sherman 1882, unnumbered fig., p. 178).

\section{The geoid}

Between 1818 and 1832, Gauss undertook a survey of the Kingdom of Hannover. As this proceeded, he realised that the geometric model of the figure of the Earth as an oblate ellipsoid was inadequate and wrote:

what we call the surface of the Earth in a mathematical sense is nothing else but that surface, which everywhere intersects the direction of gravity at right angles, and of which the surface of the oceans is part (Gauss 1828, transl. Fischer 1975, p. 23).

Stokes (1849), in his exposition of what became known as Stokes theorem, offered the hope that such a surface could be computed from gravity data, and hence calculate the separation between the observed equipotential surface and that formed by the calculated geometric model. In 1872, Gauss' former student, the mathematician and physicist, Johann Benedict Listing (1808-1882) coined the term geoid for the equipotential surface.

In 1882, Pierce, chief geodesist of the U.S. Coast and Geodetic Survey (CGS), and the English army officer and geodesist, Maj. John Herschel (1837-1921), lately returned from twenty-nine years service with the Great Trigonometrical Survey of India, and having just completed linkage between the American and British gravity reference values by swinging the same invariable pendulums at London and Washington DC, met at a private meeting hosted by the CGS in Washington, to consider the future of gravity determination. Despite disagreements on detail throughout the proceedings (they could not even agree on what was meant by an "invariable pendulum"), both did agree (Pierce 


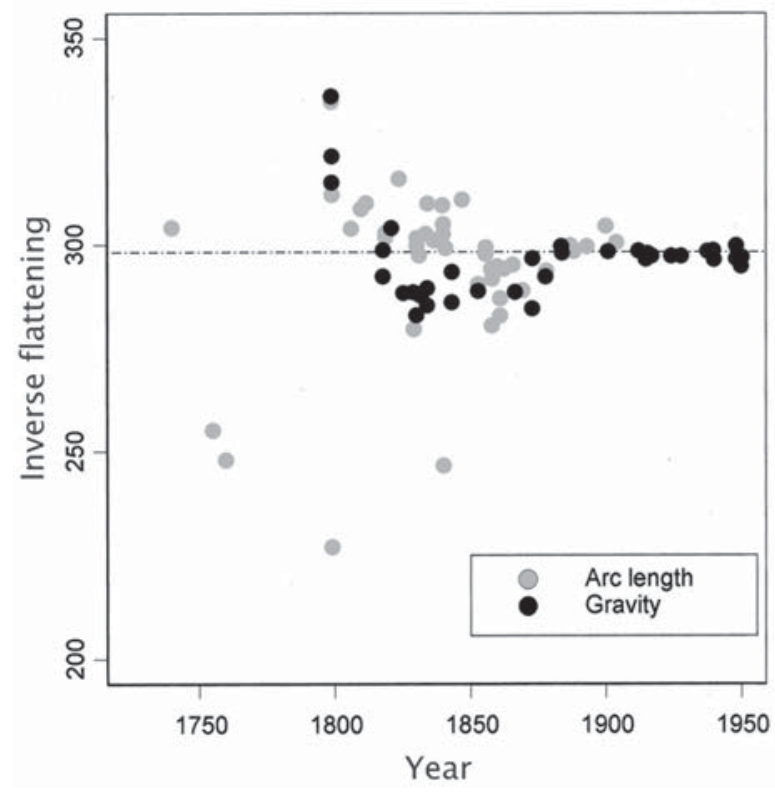

Figure 8. Difference in estimates of flattening of the Figure of the Earth from arc-length and gravity measurements from 1800 to 1920 (data from Strasser 1957). The results eventually converge towards an inverse flattening of 298. The 1984 U.S. Department of Defense World Geodetic System value (based on multiple sources of evidence, Warner 2002) is 298.257224 (Department of Defense 1987).

$1883 \mathrm{c}$, Herschel 1883a) that the primary purpose of a geodetical survey was "unquestionably the determination of the [E]arth's figure" (Pierce 1883c, p. 506), by which was meant

the actual (or conceivable ) continuous water surface as exemplified by the mean sea level; which surface may be everywhere nearly, though nowhere fully, represented by some assumed simple geometrical figure, such as an elliptic spheroid (Herschel 1883a, p. 510).

Furthermore, it was by now accepted that the values of flattening derived from both arc-length (astrogeodetic) data and gravity measurements had essentially converged to a near-constant value (Figure 8), although it was believed that the gravity-derived values were to be preferred (Pierce 1883c). In a letter sent prior to the meeting, Herschel wrote "we do actually know the mean figure of the [E] arth [geoid] as well as we can know it so long as the irregularities which deform it remain unknown" (Herschel 1883b, p. 504; emphasis as in original). To Pierce's evident astonishment, at the meeting itself, Herschel proposed that since the mean figure was now essentially established, it would be better to focus future effort "to enlarge our knowledge of the irregularities offigure rather than to aim at improving the mean figure" and that to accomplish this "a group of contiguous determinations of a low order of accuracy would always be more valuable than a single one of the very highest order (Herschel 1883a, pp. 511-512; emphasis as in original). What was needed was a world-wide enlargement of the network of gravity stations (especially at high latitudes) using a simpler apparatus to "obtain at least a rude measure of the local deflection ... even though it should fail to rival the pendulum in accuracy" (Herschel 1883a, p.512). 
When Clairaut formulated his theorem in the eighteenth century there was, of course, no knowledge that the Earth contained a dense core. This defect in the theory was independently remedied by the English astronomer and mathematician George Darwin (1845-1912) in 1900 and the German geodesist, Friedrich Robert Helmert (1843-1917) in 1901. Both derived improved theoretical approximations for the shape of the geoid by introducing a second-order term in $f^{2}$, to take into account a slight departure from a pure ellipsoid. The Helmert (1901) model was

hence:

$$
\begin{gathered}
g=g_{\mathrm{e}}\left[1+c_{1} \sin ^{2} \theta+c_{2} \sin ^{2}(2 \theta)\right], \\
\text { where } c_{1}=(5 k / 2-f-17 k f / 14) \text { and } c_{2}=\left(f^{2}-5 k f\right) / 8 .
\end{gathered}
$$

$$
g=g_{\mathrm{e}}\left[1+0.005302 \sin ^{2} \theta-0.000007 \sin ^{2}(2 \theta)\right]
$$

where $g_{\mathrm{e}}=978.030 \mathrm{mGal}(1 \mathrm{mGal}$ is $0.001 \mathrm{Gal}$, a unit named after Galileo Galilei; $1 \mathrm{Gal}$ $\left.=1 \mathrm{~cm} \mathrm{~s}^{-2}\right) ; k=1 / 289$ as before; and $f=1 / 298.3$.

This was the first of a long succession of proposed models, each of which tended to fit the real Earth better over some continents than others. As remarked by Warner (2002, p. 364) "The ellipsoid is regular, imaginary and contested .... The geoid, irregular but real" consequently, as Herschel recognised, "the ellipsoidal parameters .... lost the interest they once commanded" (Fischer 1975, p. 51). As Herschel realised, filling in the detail of the irregular surface by all means possible became the goal. By the early 1950s, this included satellite-derived data (O'Keefe 1959). Foremost in this effort, has been the work of military geodesists, as detailed knowledge of the geoid provides vital information to enable accurate targeting of ballistic missiles (Warner 2002). Li and Gotze (2001) review the place of the ellipsoid and the geoid in modern geophysics.

\section{The role of geology}

As pendulums were carried with scientific expeditions to all parts of the world, more field data continued to accumulate, and it became increasingly clear that matters were not as simple as it had seemed to the early theorists. It has already been noted that some early observers wondered if the nature of the rocks making up the terrain might have an effect on the absolute, or relative, intensity of gravity measured at a station (apart from their possible control of its topography), but no serious consideration was given to investigating this aspect until 1845 when the British Astronomer Royal, George Biddell Airy (18011892) reviewed pendulum observations for an article in the Encyclopaedia Metropolitana. He attempted a statistical assessment of what he considered to be forty-nine "first class" and fourteen "second class" determinations of the one-second pendulum length (to which all necessary corrections had already been applied) at his disposal. Using Mayer's method, his fitted equation (Figure 9) was

$$
l=39.01677+0.20027 \sin ^{2} \theta \text { in, }
$$

corresponding to a flattening of 1/282.88. As had Sabine, Airy used his estimates of $l_{\mathrm{e}}$ and $c$ to calculate the theoretical pendulum lengths at each station and the corresponding "error in length" (residual). He drew two conclusions from his analysis:

1. The observations that we have called second-rate .... are perfectly useless for the investigation of the Earth's form. 2. Upon scrutinising the errors of the first-rate observations, it would seem that, caeteris paribus [other things being equal], gravity is greater on islands than on continents. This is a conclusion, however, that cannot be adopted till the correction for elevation is ascertained with greater certainty. (Airy 1845, p. 230). 


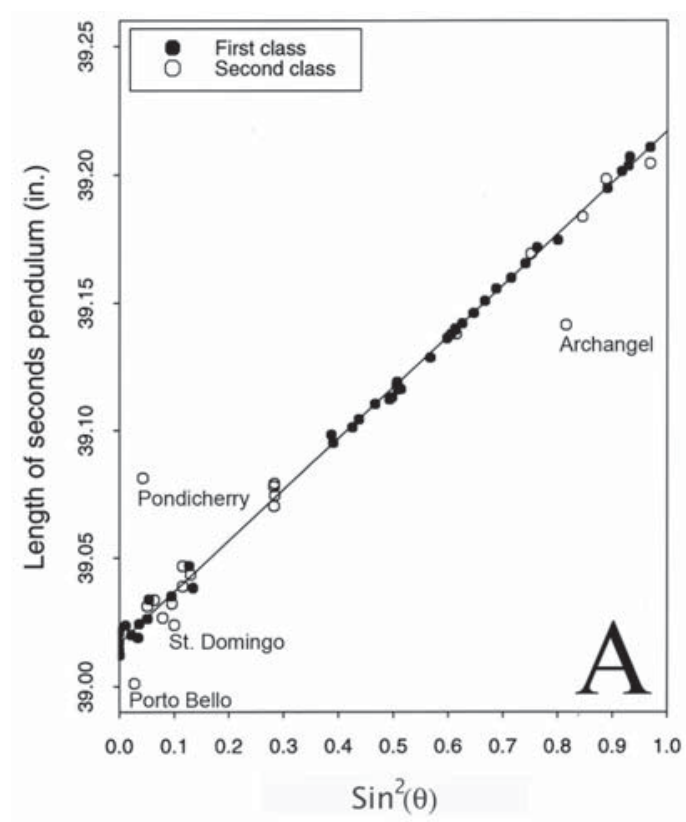

Figure 9. Airy's fit, by Mayer's (1750) method, to 49 "first class" and 14 "second class" worldwide observations of seconds pendulum length as a function of latitude. (A) Data points and fitted equation; (B) boxplots of errors in the fit, classified by type of station. The data appear in tabular form in Airy (1845).

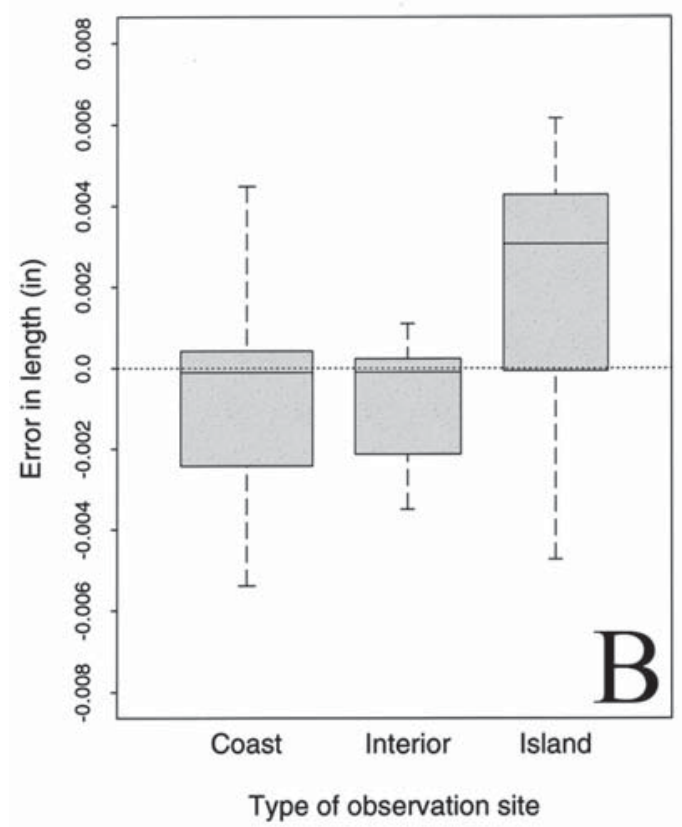

The matter which concerned him most was that there appeared to be a significant difference between the value of flattening given by the gravity measurements $(0.003535)$ and that which he found by applying the same statistical technique to eighteen measurements of arc length (0.003352). He tried introducing an additional cross-product term $\left(\sin ^{2} \theta \cos ^{2} \theta\right)$ into the equation for pendulum length, but it did not substantially improve the coincidence of the results. 
Unable to offer a satisfactory explanation, Airy's conclusion, that there was something odd about gravitational results made on islands, was close to the truth. It is now known that many of the older gravity measurements were often made on islands or in coastal areas and did not sufficiently take into account their different distributions of mass compared to continental regions. In consequence, the estimates of flattening from pendulum measurements were generally larger (or inverse flattening smaller, Figure 9) than those from arc-length. This situation persisted until 1886, when the German geodesist Friedrich Robert Helmert (1843-1917) first demonstrated the presence of this source of error and showed how to correct for it.

Pendulums continued to be used for the absolute determination of the intensity of gravity at national laboratories into the 1960s (Cook 1965), but despite the development of the Askania and Gulf multiple-pendulums in the United States, other than in marine work, they had only a short-lived appearance in geological exploration between 1925 and the late 1930s (Sweet 1978, pp. 25, 315, 365). Following the First World War, new instrumentation (the torsion balance and later the gravimeter) proved to be more portable and of superior accuracy in the field to the pendulum and enabled gravity surveying to become a successful tool in geological exploration. The second part of this paper will describe the development of gravity-measurement as it came to play an increasingly important part in the interpretation of geology through the nineteenth century into the 1960s. Later technological innovations are discussed by Chapin (1998).

\section{ACKNOWLEDGEMENTS}

The anonymous referees are thanked for their comments on the manuscript.

\section{REFERENCES}

Adrain, Robert, 1808. Research concerning the probabilities of the errors which happen in making observations. The Analyst or Mathematical Museum, Philadelphia 1: 93-109.

Adrain, Robert, 1818. Investigation of the Figure of the Earth, and of the Gravity in different Latitudes. Transactions of the American Philosophical Society n.s. 1: 119-135.

Airy, George B. 1845. Figure of the Earth. In Encyclopaedia Metropolitana, Edward Smedley, Hugh J. Rose and Henry J. Rose (eds.), 5: 165-240. London: Fellowes \& Rivington.

Anonymous, 1674. Observations physiques. Histoire de l'Académie Royale des Sciences. Depuis son établissement en 1666, jusqu'à 1686 1: 176-178.

Anonymous, 1690. Astromomie. Histoire de l'Académie Royale des Sciences. Depuis 1686, jusqu'à son Renouvellement en 1699 2: 94-104.

Baily, Francis, 1832. On the correction of a Pendulum for the reduction to a vacuum, together with some remarks on some anomalies observed in pendulum experiments. Philosophical Transactions of the Royal Society 122: 399-492.

Bernoulli, Daniel, 1750. Recherches méchaniques et astronomiques, sur la Question proposée par l'Académie Royale des Sciences pour l'année 1745. In Pièces qui ont remporté les prix fondez dans l'Académie royale des sciences en 1747 Sur la meilleure manière de trouver l'heure en Mer. Selon la fondation faite par M. Rouillé de Meslay, ancien conseiller au Parlement, Académie des Sciences, 1-110. Paris: Gabr. Martin, J.B. Coignard and H.L. Guerin.

Bessel, Friedrich W. 1828. Untersuchungen über die Länge des einfachen Secundenpendels. Abhandlungen der Königlichen Akademie der Wissenschaften zu Berlin 1826: 1-254. [French translation in Wolf 1889a, IV: 124-223; V: 1-70].

Bessel, Friedrich W. 1849. Construction eines symmetrisch geformten Pendels mit reciproken Axen von Bessel. Astronomische Nachrichten 30: 1-6. [French translation in Wolf 1889a, V: 420-426].

Biot, Jean-Baptiste, 1818a. Notice sur les opérations d'Espagne et d'France; Lue à la séance publique de la 
classe des Sciences de l'Institut, le 2 janvier 1810. In Notice sur les opérations exécutées en Espagne, en France, en Angleterre et en Écosse, Pour mesurer la courbure de la terre et la variation de la pesanteur sur l'arc du méridien qui s'éntend depuis l'île de Formentera, la plus australe des Pythiuses, jusqu'à Unst, la plus boreale des îles Shetland, 1-30. Paris: Académie des Sciences de l'Institut de France.

Biot, Jean-Baptiste, 1818b. Notice sur les opérations d'Angleterre et d'Écosse; Lue à la séance publique annuelle des quatre Académies, le 24 avril 1818. In Notice sur les opérations exécutées en Espagne, en France, en Angleterre et en Écosse, Pour mesurer la courbure de la terre et la variation de la pesanteur sur l'arc du méridien qui s'éntend depuis l'île de Formentera, la plus australe des Pythiuses, jusqu'à Unst, la plus boreale des îles Shetland, 31-60. Paris: Académie des Sciences de l'Institut de France.

Biot, Jean-Baptiste, 1829. Mémoire sur la Figure de la Terre. Mémoires de l'Académie royale des Sciences de l'Institut de France. 8: 1-56.

Birch, Thomas, 1756. The History of the Royal Society of London, for Improving of natural Knowledge, From Its First Rise. 2 volumes. London: Millar [reprinted 1967, Brussels: Culture et Civilisation].

Borda, Jean-Charles de. and Cassini de Thury, Jacques-Dominique, 1810. Expériences pour connoître la longeur du Pendule qui bat les secondes à Paris. In Base du système métrique décimal, ou mesure de l'arc du méridien compris entre les parallèles de Dunkerque et Barcelone, exécutée en 1792 et années suivantes, Jean-Baptiste Delambre and Pierre Méchain (eds), volume III. Paris: Baudouin, 337-401.

Bouguer, Pierre, 1749. La Figure de la terre, Déterminée par les observations de Messieurs Bouguer et de la Condamine, de l'Académie Royale des Sciences, envoyés par ordre du Roy au Pérou pour observer aux environs de l'Equateur. Avec une Relation abregée de ce Voyage, qui contient la description du Pays dans lequel les Opérations ont été faites. Paris: Charles-Antoine Jombert.

Bowie, William, 1920. Present Status of Geodesy and Some of the Problems of this Branch of Geophysics. Proceedings of the National Academy of Sciences of the United States of America, 6: 545-555.

Bruhns, Carl and Hirsch, Adolf (eds.), 1878. Verhandlungen der vom 27. September bis 2. Oktober $1877 \mathrm{zu}$ Stuttgart abgehaltenen Funften allgemeinen Conferenz der Europaïschen Gradmessung. Berlin: G. Reimer.

Burger, William H. 1911. The measurement of the flexure of pendulum supports with the interferometer. Appendix 6. In Report of the Superintendent of the Coast and Geodetic Survey showing the progress of the work from July 1, 1909 to June 30, 1910, 431-449. Washington. Government Printing Office.

Cajori, Florian (ed.), 1934. Sir Isaac Newton's Mathematical Principles of Natural Philosophy. Vol. II, Book III. The System of the World. Third edition. Translated from the original Latin [by] Andrew Motte, 1729. London: The Royal Society. [reprinted 1962, Berkley, CA: University of California Press].

Chapin, D. 1998. Gravity instruments: Past, present, future. The Leading Edge 17: 100-112.

Clairaut, Alexis C. 1743. Théorie de la Figure de la Terre, tirée des principes de l'Hydrostatique. Paris: David. Cook, Alan H. 1965. The absolute determination of acceleration due to gravity. Metrologia 1: 84-114.

Cook, Alan H. 1998. Edmond Halley. Charting the Heavens and the Seas. Oxford: Clarendon Press.

Darwin, George H. 1900. The theory of the figure of the Earth carried to the second order of small quantities. Monthly Notices of the Royal Astronomical Society 60: 82-124.

Davies, Gordon L. 1964. Robert Hooke and his conception of earth-history. Proceedings of the Geologists' Association 75: 493-498.

Débarbat, Suzanne and Ten, Antonino E. (eds.) 1993. Mètre et Système Métrique. Paris: Observatoire de Paris.

Department of Defense, 1987. Department of Defense World Geodetic System 1984 - Its definition and relationships with local geodetic coordinate systems. Defense Mapping Agency Technical Report 8350.2. Washington D.C.: Department of Defense.

Fischer, Irene, 1975. The Figure of the Earth - Changes in concepts. Geophysical Surveys 2: 3-54.

Freycinet, C. Louis D. de. 1826. Voyage autour du monde, entrepris par ordre du Roi, exécuté sur les corvettes "L'Uranie" et "La Physicienne", pendant les années 1817 à 1820. Observations du pendule. Paris: Pillet Aîné.

Galilei, Galileo, 1632. Dialogo sopra i due massimi sistemi del mondo, Tolemaico e Copernicano. Firenze: Giovanni Batista Landini. [translated 1953 by Drake Stillman. Dialogue Concerning the Two Chief World Systems: Ptolemaic and Copernican. Berkley, CA: University of California Press; revised edition. 1967].

Galilei, Galileo, 1638. Discorse e Dimostrazioni matematiche intorno a due nuove Scienze attenenti alla Meccanica ed ai movimenti locali. Altrimenti, dialogi delle Scienze. Leida: Elzevir. [translated 1914 by Henry Crew and Alfonso De Salvio. Dialogues concerning two new sciences, New York: Macmillan; reprinted 1952, New York: Dover]. 
Gauss, Carl F. 1809. Theoria Motus Corporum Coelestium in Sectionibus Conicis Solem Ambientium. Hamburg: Perthes and Besser.

Gauss, Carl F. 1828. Bestimmung des Breitenunterschiedes zwischen den Sternwarten von Göttingen und Altona: durch Beobachtungen am Ramsdenschen Zenithsector. Göttingen: Vandenhoeck and Ruprecht.

Gunther, R.T. 1930. Early Science in Oxford. Vol. VI. The life and work of Robert Hooke (Part 1). Oxford: Printed for the author.

Hald, Anders, 1998. A History of Mathematical Statistics From 1750 to 1930. New York: Wiley.

Hall, Donald.H. 1976. History of the Earth Sciences during the Scientific and Industrial revolutions. Amsterdam: Elsevier.

Heiland, Carl A. 1940. Geophysical Exploration. New York: Prentice-Hall.

Heilbron, John L. 1993. Weighing imponderables and other quantitative science around 1800. Historical Studies in the Physical and Biological Sciences, supplement to 24 (1). Berkeley, CA: University of California Press.

Helmert, Friedrich R. 1901. Der normale Teil der Schwerkraft im Meeresniveau. Sitzungsberichte der Königlich Preussischen Akademie der Wissenschaften 1901: 328-336.

Herschel, John E. 1883a. General remarks upon gravity determinations. In: Appendix no. 22. Report of a Conference on gravity determinations, held at Washington, D.C. in May 1882. Report of the Superintendent of the U.S. Coast and Geodetic Survey showing the progress of the work during the Fiscal Year ending with June, 1882. 510-512. Washington: Government Printing Office.

Herschel, John E. 1883b. Letter to Prof. J.E. Hilgard [New York, May 5, 1882]. In: Appendix no. 22. Report of a Conference on gravity determinations, held at Washington, D.C. in May 1882. Report of the Superintendent of the U.S. Coast and Geodetic Survey showing the progress of the work during the Fiscal Year ending with June, 1882. 504-505. Washington: Government Printing Office.

Hilgard, Julius E. 1883. Pendulum observations. Report of the Superintendent of the U.S. Coast and Geodetic Survey showing the progress of the work during the Fiscal Year ending with June, 1881. 26. Washington: Government Printing Office.

Hooke, Robert, 1678. Lectures de Potentia Restitutiva, or of Spring Explaining the power of springing Bodies. London: John Martin.

Howarth, Richard J. 2001. A History of Regression and Related Model-Fitting in the Earth Sciences (1636?2000). Natural Resources Research 10: 241-286.

Huygens, Christiaan, 1658. Horologium. Hagae: Adrian Vlacq [translated 1970 by Ernest L. Edwardes. The Timepiece. Antiquarian Horology 7: 35-52].

Huygens, Christiaan, 1661. De centro oscillationis sive Ad invenienda perpendicula simplicia isochrona propositis perpendiculis compositis. In Oeuvres complètes de Christiaan Huygens, Société Hollandaise des Sciences 1929, 16: 414-433. La Haye: Nijhoff.

Huygens, Christiaan, 1673. Horologium osillatorium, sive de motu pendulorum ad horologia aptato demonstrationes geometricae. Paris: F. Muget. [translated with notes by Richard J. Blackwell. 1986. Christiaan Huygens' The pendulum clock, or, Geometrical demonstrations concerning the motion of pendula as applied to clocks. Ames, IO: Iowa State University Press].

Inwood, Steven, 2002. The Man Who Knew Too Much. The strange and inventive life of Robert Hooke, 16351703. London: Macmillan.

Jakosky, Jay J. 1940. Exploration geophysics. Los Angeles: Times-Mirror.

Kater, Henry, 1818. Experiments relating to the Pendulum vibrating seconds of time in the latitude of London. Philosophical Transactions of the Royal Society 108: 33-102.

Kater, Henry, 1819. An account of experiments for determining the variation in length of the pendulum vibrating seconds, at the principal stations of the Trigonometrical Survey of Great Britain. Philosophical Transactions of the Royal Society 109: 337-508.

Kühnen, Friedrich and Furtwängler, Philipp, 1906. Bestimmung der absoluten Grösze der Schwerkraft zu Potsdam: mit Reversionspendeln. Veröffentlichung des Königlichen Preuszischen Geodätischen Institutes, n.f. 27. Berlin : Stankiewicz.

Koyré, Alexandre, 1953. An experiment in measurement. Proceedings of the American Philosophical Society 97: $222-237$.

Lambert, Johann H. 1765. Beyträge zum Gebrauche der Mathematikund deren Anwendung, volume I. Berlin: Verlag der Buchhandlung der Realschule.

Laplace, Pierre S. 1799 [An VII].Traité de Méchanique Céleste volume II. Paris: Crapelet.

Legendre, Adrien M. 1805. Nouvelles méthodes pour la determination des orbites des comètes. Paris: Courcier. 
Lenzen, Victor F. and Multhauf, Robert, P. 1965. Development of Gravity Pendulums in the 19th Century. Contributions from the Museum of History and Technology: Paper 44. United States National Museum Bulletin 240: 301-347.

Leopold, J.H. 1989. Clockmaking in Britain and the Netherlands. Notes and Records of the Royal Society of London 43: 155-165.

Li, Xiong and Götze, Hans-Jürgen, 2001. Tutorial: Ellipsoid, geoid, gravity, geodesy, and geophysics. Geophysics, 66: 1660-1668.

Listing, Johann B. 1872. Über unsere jetzige Kenntniss der Gestalt und Grosse der Erde. Gottingen: Dieterich.

Maclaurin, Colin, 1740. De causa physica fluxus ac refluxus maris. Pièces de prix de l'Académie Royale des Sciences 195. Recueil des pieces qui ont remporte le prix de l'Academie en 1740-41, 4: 193-234. Paris: L'Académie Royale des Sciences.

Mairan, Jean-Jacques D. de. 1738 Expériences sur la longeur du pendule a secondes a Paris. Histoire de l'Académie Royale des Sciences 1738 [for 1735]: 153-220.

Maire, Christopher \& Boscovich, Ruggerio J. 1770. Voyage astronomique et geographique, dans l'état de l'eglise, entrepris par l'ordre et sous les auspices du Pape Benoit XIV, Pour mesurer deux dégrés de méridien, et corriger la Carte de l'Etat ecclésiastique. ... Traduit du latin [Fr. Hugon]. Paris: M.N. Tilliard.

Maupertuis, Pierre L.M. de. 1738. Figure de la Terre déterminée par les observations ... faites par ordre du roi au cercle polaire. Amsterdam: Catuff.

Mayer, Tobias, 1750. Abhandlung über die Umwalzung des Monds un seine Axe und die scheinbare Bewegung der Mondsflecten. Kosmographische Nachrichten und Sammlungen, 1750 [for 1748]: 52 183.

Mersenne, Marin, 1636. Harmonie universelle contenant la théorie et la pratique de la musique ou il est traite de la nature des sons et des mouvements des consonances et des dissonances, des genres des modes, de la composition de la voix, des chants et de toutes sortes d'instrumens harmoniques. 2 volumes. Paris: Sebast. Cramoisy. [reprinted 1986 with introduction by François Lesure. Abbeville: Editions du Centre National de la Recherche Scientifique].

Mersenne, Marin, 1644. De Ballistica et Acontismologia, su de sagittarum, jaculorum et aliorum missilivm. In Cogitata Physico Mathematica. In quibus tam naturae quàm artis effectus admirandi certissimis demonstrationibus explicantur. VI, 38-46. Parisiis: Antonii Bertier.

Nettleton, Lewis L. 1940. Geophysical Prospecting for Oil. New York: McGraw-Hill.

Newton, Isaac, 1687. Philosophiae naturalis Principia mathematica. Londini: Societas Regiae.

Newton, Isaac, 1713. Philosophiae naturalis Principia mathematica. Second edition. Cantabrigiae: Societas Regiae.

Newton, Isaac, 1726. Mathematical Principles of Natural Philosophy. Vol. II, Book III. The System of the World. Third edition. Translated from the original Latin [by] Andrew Motte, 1729. The Royal Society, London. Revised, 1934, with additional notes by Florian Cajori, 397-680 [reprinted 1962, Berkley, CA: University of California Press].

O'Keefe, John.A. 1959. Zonal harmonics of the Earth's gravitational field and the basic hypothesis of geodesy. Journal of Geophysical Research 64: 2389-2392.

Oldroyd, David. 1996. Thinking about the Earth: A history of ideas in geology. London: Athlone.

Pierce, Charles S. 1883a. On the flexure of pendulum supports. Appendix 14. Report of the Superintendent of the U.S. Coast and Geodetic Survey showing the progress of the work during the Fiscal Year ending with June, 1881, 359-441. Washington: Government Printing Office.

Pierce, Charles S. 1883b. Opinions concerning the conduct of gravity work. In: Appendix no. 22. Report of a Conference on gravity determinations, held at Washington, D.C. in May 1882. Report of the Superintendent of the U.S. Coast and Geodetic Survey showing the progress of the work during the Fiscal Year ending with June, 1882, 512-516. Washington: Government Printing Office.

Pierce, Charles S. 1883c. Six reasons for the prosecution of pendulum experiments. In: Appendix no. 22. Report of a Conference on gravity determinations, held at Washington, D.C. in May 1882. Report of the Superintendent of the U.S. Coast and Geodetic Survey showing the progress of the work during the Fiscal Year ending with June, 1882, 506-508. Washington: Government Printing Office.

Plantamour, Emile, 1866. Expériences faites à Genève avec le pendule à réversion. Genève: H. Georg. Poynting, John H. 1894. The mean density of the Earth. London: Griffin.

Prony, Gaspard C.-F.-M. R.-de. 1801. Méthode pour déterminer la longeur du pendule simple qui bat les secondes et pour trouver, en général, les positions des centres de gravité et d'oscillation et le moment d'inertie d'un corps de forme quelconque. Mémoire présenté à la Première Classe de l'Institut dans la 
séance du 11 vendémiaire, an IX [3 Oct. 1801]. In Collection de Mémoires relatif a la Physique. Tome IV. Mémoires sur le pendule précédés d'une bibliographe, Christian J. E. Wolf(ed.), 1889, 65-76. Paris: Gauthier-Villars.

Reid, Thomas, 1830. Horology. In The Edinburgh Encyclopaedia, David Brewster (ed.) 12: 114-175. Edinburgh: Blackwood \& Waugh.

Riccioli, Giovanni Battista, 1651. Almagestum novum astronomiam veterem novamque complectens observationibus aliorum, et propriis Novisque Theorematibus, problematibus, ac Tabulis promotam. Bononiae: V. Benatij.

Richer, Jean, 1729. Observations astronomique et physiques faites en l'Isle de Caienne. Mémoires de l'Académie Royale des Sciences depuis 1666 jusqu'à 1699, 7: 233-326.

Richer, Jean,1821. An account of experiments to determine the acceleration of the pendulum in different latitudes. Philosophical Transactions of the Royal Society, 111: 163-190.

Richer, Jean,1825. An Account of Experiments to Determine The Figure of the Earth by means of the Pendulum Vibrating Seconds in Different Latitudes; as wells as various other subjects of philosophical enquiry. London: John Murray.

Richer, Jean,1829. On the reduction to a vacuum of the vibrations of an invariable pendulum. Philosophical Transactions of the Royal Society, 119: 207-239.

Schott, Charles A. 1883. Notes on determination of gravity. In: Appendix no. 22. Report of a Conference on gravity determinations, held at Washington, D.C. in May 1882. Report of the Superintendent of the U.S. Coast and Geodetic Survey showing the progress of the work during the Fiscal Year ending with June, 1882, 508-510. Washington: Government Printing Office.

Sherman, O.T. 1882. A pendulum study. American Journal of Science, Third series, 24: 175-180.

Smith, James R. 1986. From Plane to Spheroid. Determining the Figure of the earth from 3000 B.C. to the 18th Century Lapland and Peruvian Survey Expeditions. Rancho Cordova CA: Landmark Enterprises.

Smith, William, 1815. A delineation of the strata of England and Wales, with part of Scotland; exhibiting the collieries and mines, the marshes and fen lands originally overflowed by the sea, and the varieties of soil according to variations in the substrata, illustrated by the most descriptive names. London: J. Cary.

Société Hollandaise des Sciences. 1888 - 1950. Oeuvres complètes de Christiaan Huygens. 23 volumes. La Haye: Nijhoff.

Sternek, Robert von. 1887. Der neue Pendelapparat des Kaiserlich-Königlichen Militär-Geographischen Institutes. Mittheilungen des Kaiserlich-Königlichen Militär-Geographischen Institutes in Wien 7: 83116.

Stigler, Steven M. 1986. The History of Statistics. Cambridge, MS: Harvard University Press.

Strasser, Georg. 1957. Ellipsoidische Parameter der Erdfigur(1800-1950). Deutsche Geodätische Kommission. Reihe A, Höhere Geodäsie Heft 19. München: Bayerischen Akademie der Wissenschaften.

Stokes, George G. 1849. On the variation of gravity at the surface of the Earth. Transactions of the Cambridge Philosophical Society 8: 672-695.

Stokes, George G. 1856. On the Effect of the Internal Friction of Fluids on the Motion of Pendulumns. Transactions of the Cambridge Philosophical Society 9: 8-106.

Swick, Clarence H. 1931. Determination of " $g$ " by means of the free swinging pendulum. In: Physics of the Earth II- The Figure of the Earth, Subsidiary Committee on the Figure of the Earth. Bulletin of the National Research Council, Washington DC, 78: 151-166.

Todhunter, Isaac, 1873. History of the theories of attraction and the figure of the earth. 2 volumes. London: Macmillan.

Toomer, Gerald J. (translator and ed.) 1984. Ptolemy's Almagest. New York: Springer-Verlag [reprinted 1998, Princeton: Princeton University Press].

Varin, Jean, Des Hayes, Jean and de Glos, Guillaume, 1729. Voyages au Cap Verd, en Afrique et aux Isles de l'Amérique. Mémoires de l'Académie Royale des Sciences depuis 1666 jusqu'en 1699, 7: 431-459.

Vening Meinesz, Andries F. 1923. Observations de pendule dans le Pays-Bas, 1913-21. Delft: Technische Boekhandel en Drukkerij.

Vening Meinesz, Andries F. 1925. The determination of gravity at sea in a submarine. The Geographical Journal 65: 501-514.

Warner, Deborah J. 2002. Political Geodesy: the Army, the Air Force, and the World Geodetic System of 1960. Annals of Science 59: 363-389.

Westfall, Richard S. 1983. Never at Rest. A Biography of Isaac Newton. Cambridge: Cambridge University Press.

Wolf, Christian J.E. (ed.) 1889a. Collection de Mémoires relatif a la Physique. Tome IV. Mémoires sur le 
pendule précédés d'une bibliographe; Tome V. Mémoires sur le pendule. Second partie. Paris: GauthierVillars [for Société Française de Physique].

Wolf, Christian J.E. 1889b. Introduction historique. In Wolf 1889a, IV: i-xlii.

Wolf, Christian J.E. 1889c. Bibliographie du pendule. Liste chronologique des oeuvrages et mémoires relatifs a la théorie et aux applications du pendule, publiés depuis 1629 jusqu'a la fin de 1885 . In Wolf 1889 a, IV: B1-B216. 